\title{
Tumor-secreted miR-214 induces regulatory T cells: a major link between immune evasion and tumor growth
}

Yuan Yin ${ }^{1,6, *}$, Xing Cai ${ }^{1, *}$, Xi Chen ${ }^{1, *}$, Hongwei Liang ${ }^{1, *}$, Yujing Zhang ${ }^{1}$, Jing Li $^{1}$, Zuoyun Wang ${ }^{2}$, Xiulan Chen ${ }^{3}$, Wen Zhang ${ }^{1}$, Seiji Yokoyama ${ }^{4}$, Cheng Wang ${ }^{1}$, Liang $\mathrm{Li}^{1}$, Limin $\mathrm{Li}^{1}$, Dongxia Hou ${ }^{1}$, Lei Dong ${ }^{1}$, Tao Xu ${ }^{5}$, Takachika Hiroi ${ }^{4}$, Fuquan Yang ${ }^{3}$, Hongbin $\mathrm{Ji}^{2}$, Junfeng Zhang ${ }^{1}$, Ke Zen ${ }^{1}$, Chen-Yu Zhang ${ }^{1}$

${ }^{1}$ Jiangsu Engineering Research Center for MicroRNA Biology and Biotechnology (JERC-MBB), State Key Laboratory of Pharmaceutical Biotechnology, School of Life Sciences, Nanjing University, 22 Hankou Road, Nanjing, Jiangsu 210093, China; ${ }^{2}$ State Key Laboratory of Cell Biology, Institute of Biochemistry and Cell Biology, Shanghai Institutes for Biological Sciences, Chinese Academy of Sciences, 320 Yue-Yang Road, Shanghai 200031, China; ${ }^{3}$ Key Laboratory of Protein and Peptide Pharmaceuticals \& Laboratory of Proteomics, Institute of Biophysics, Chinese Academy of Sciences, Beijing 100101, China; ${ }^{4}$ Department of Allergy and Immunology, The Tokyo Metropolitan Institute of Medical Science, Tokyo 156-8506, Japan; ${ }^{5}$ National Laboratory of Biomacromolecules, Institute of Biophysics, Chinese Academy of Sciences, Beijing 100101, China; ${ }^{6}$ Wuxi Oncology Institute, the Affiliated Hospital of Jiang Nan University, Wuxi, Jiangsu 214062, China

An increased population of $\mathrm{CD}^{+} \mathrm{CD}^{\mathrm{h}}{ }^{\text {high }} \mathrm{Foxp}^{+}$regulatory $\mathrm{T}$ cells (Tregs) in the tumor-associated microenvironment plays an important role in cancer immune evasion. However, the underlying mechanism remains unclear. Here we observed an increased secretion of miR-214 in various types of human cancers and mouse tumor models. Tumor-secreted miR-214 was sufficiently delivered into recipient $\mathrm{T}$ cells by microvesicles (MVs). In targeted mouse peripheral CD4 ${ }^{+} \mathrm{T}$ cells, tumor-derived miR-214 efficiently downregulated phosphatase and tensin homolog (PTEN) and promoted Treg expansion. The miR-214-induced Tregs secreted higher levels of IL-10 and promoted tumor growth in nude mice. Furthermore, in vivo studies indicated that Treg expansion mediated by cancer cell-secreted miR-214 resulted in enhanced immune suppression and tumor implantation/growth in mice. The MV delivery of anti-miR-214 antisense oligonucleotides (ASOs) into mice implanted with tumors blocked Treg expansion and tumor growth. Our study reveals a novel mechanism through which cancer cell actively manipulates immune response via promoting Treg expansion.

Keywords: secreted microRNA; regulatory T cell; PTEN; microvesicle; immune evasion; tumor

Cell Research (2014) 24:1164-1180. doi:10.1038/cr.2014.121; published online 16 September 2014

\section{Introduction}

Tumors develop multiple potent and overlapping mechanisms to mediate immune evasion $[1,2]$. One such mechanism involves an increase in the population of $\mathrm{CD} 4^{+} \mathrm{CD} 25^{\text {high }} \mathrm{Foxp}^{+}{ }^{+}$regulatory $\mathrm{T}$ cells (Tregs), a subset

\footnotetext{
*These four authors contributed equally to this work.

Correspondence: Chen-Yu Zhang ${ }^{\mathrm{a}}$, Ke Zen ${ }^{\mathrm{b}}$, Junfeng Zhang

âE-mail: cyzhang@nju.edu.cn

${ }^{b}$ E-mail: kzen@nju.edu.cn

${ }^{\circ}$ E-mail: jfzhang@nju.edu.cn

Received 4 April 2014; revised 18 July 2014; accepted 5 August 2014; published online 16 September 2014
}

of $\mathrm{CD}^{+} \mathrm{T}$ cells that plays an important role in maintaining self-tolerance and modulating immune responses [3-5]. Tregs are increased during tumorigenesis $[6,7]$. Tumor cells can also efficiently recruit Tregs to evade the host immune response [2]. Due to the importance of Tregs in tumor immune evasion, the depletion of Tregs is a potential therapy for cancer $[8,9]$. Although multiple factors, such as IL-2 [10] and TGF- $\beta[11,12]$, are responsible for the expansion of Tregs, the precise mechanism by which tumor cells induce Tregs remains poorly understood.

The discovery of microRNAs (miRNAs), a class of noncoding RNAs with lengths of approximately $22 \mathrm{nu}-$ cleotides, has revealed a new layer of gene regulation in 
biological processes. Because miRNAs are abnormally expressed in tumors, an altered miRNA expression pattern is generally regarded as a major feature of tumorigenesis. Depending on the specific miRNAs and the targets in certain tumor types, miRNAs can function as either oncogenes or tumor suppressors. For example, miR-214, which is an important oncogenic miRNA, can promote tumorigenesis and induce cell survival and cisplatin resistance in human ovarian cancer by targeting the 3'-untranslated region (UTR) of phosphatase and tensin homolog (PTEN), which leads to the downregulation of the PTEN protein and upregulation of the Akt pathway [13]. The differential expression of miRNAs has also been reported in $\mathrm{T}$ cell maturation and activation and the modulation of immune responses [14]. For example, miR-214, miR-21, miR-31, miR-181a, and miR-155 have been reported to play pivotal roles in $\mathrm{T}$ cell function. Rouas et al. [15] also identified the miRNA signature of natural human Tregs and the regulatory roles of miR-31 and miR-21 in Foxp3 expression. The targeting of Foxp3 by miR-155 during the development of Tregs has also been reported by several groups $[16,17]$. Despite these findings, the role of miRNAs in Treg function in tumorigenesis has not been fully elucidated.

Recently, we and others have demonstrated that cells can selectively package miRNAs into microvesicles (MVs), particularly exosomes, that are secreted under various pathophysiologic stimuli in vitro and in vivo. Through MV-cell interactions and, most likely, the endocytic pathway, MVs can efficiently deliver miRNAs into recipient cells, where they block the translation of their target genes and regulate recipient cell function [18]. Thus, secreted miRNAs can serve as a novel class of signaling molecules in mediating cell-cell communication. The identification of MV-mediated functional miRNA transport between non-adjacent cells significantly extends our understanding of the role of miRNAs. Because fast-growing tumor cells have been shown to highly express certain oncogenic miRNAs, such as miR-214 and miR-21 [19], and can generate and release high levels of miRNA-containing MVs [20], it is possible that tumor cells can actively manipulate the antitumor activities of immune cells by delivering tumor-specific miRNAs to target immune cells via an MV-based pathway.

In this study, we examined the modulation of $\mathrm{CD} 4^{+} \mathrm{C}$ D $25^{\text {high }}$ Foxp $3^{+}$Tregs by tumor cell-secreted miRNAs to determine whether tumor cells can actively secrete particular miRNAs that induce suppression activities in immune cells. We identified miR-214 as a major tumor-specific miRNA secreted by various types of cancers and demonstrated for the first time that tumor cell-secreted miR-214 can promote Treg expansion by targeting PTEN in $\mathrm{CD}^{+} \mathrm{T}$ cells, leading to host immune suppression and rapid tumor growth.

\section{Results}

miR-214 levels are elevated in tissues and plasma from cancer patients and tumor xenograft mice

To identify the secreted miRNAs that are able to regulate Tregs, the expression levels of oncogenic miRNAs, including miR-18a, miR-19a, miR-200a, miR-205, miR21, miR-210, miR-214, and miR-92a [19], were assessed in tissues from patients with breast cancer, hepatocellular carcinoma, non-small-cell lung cancer, or pancreatic cancer. Although most of the oncogenic miRNAs had elevated expression levels in the 4 types of cancer, only miR214 and miR-21 levels were increased in all 4 types of cancer (Figure 1A). The levels of the oncogenic miRNAs that were secreted into the plasma from the patients were then measured. Most of the miRNAs were increased in one or two types of cancer, but only miR-214 was significantly increased in all four types of cancer (fold change $>2$ and $P<0.05$ ) (Figure 1B). Further analysis revealed that the plasma levels of miR-214 in the tumor-bearing patients were markedly enriched in MVs (Figure 1C), by which miRNAs can be delivered into recipient cells. Secreted miR-214 levels were also investigated in mouse models. Mouse sarcoma S-180 cells and Lewis lung carcinoma (LLC) cells were used to establish a tumor xenograft mouse model. miR-214 expression levels were also increased in these two cell lines (Figure 1D). The elevation of circulating miR-214 and the enrichment of miR-214 in MVs was also observed in the two tumor xenograft mouse models (Figure 1E-1H). These results suggest that increased miR-214 secretion may occur in cancer cell biogenesis.

\section{LLC cell-secreted miR-214 promotes Treg expansion}

To determine whether secreted miR-214 was sufficiently delivered into the recipient Tregs, LLC-derived MVs containing a high level of miR-214 were incubated with primary $\mathrm{CD}^{+} \mathrm{T}$ cells in culture (Figure $2 \mathrm{~A}$ ). miR214 levels were markedly increased in the recipient $\mathrm{CD}^{+} \mathrm{T}$ cells and peaked $24 \mathrm{~h}$ post MV treatment (12fold induction) (Figure 2B), while no alterations in the levels of pre-miR-214 were observed (Figure 2C), suggesting that the elevation of miR-214 level in the CD4 $\mathrm{T}$ cells was likely due to the MV delivery of exogenous miR-214. We also measured the levels of miR-199a, premiR-199a-2, and Dnm3os post MV treatment. miR-214 and miR-199a-2 are located within the same non-coding RNA, DNM3os, and a change in endogenous miR-214 should be accompanied by a change in DNM3os and 
A

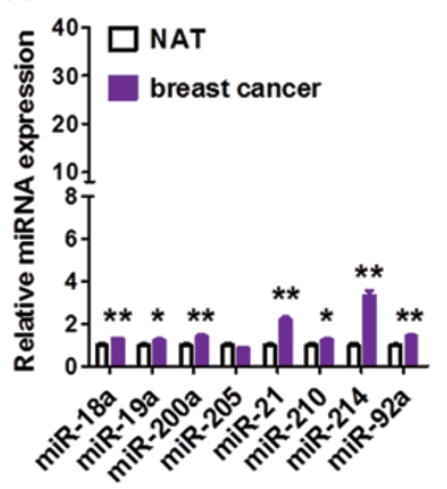

B

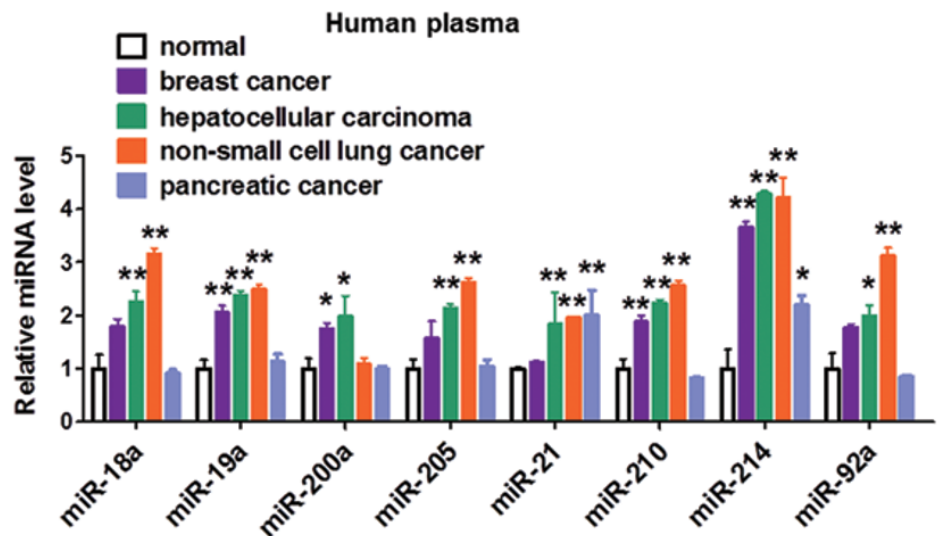

D

E

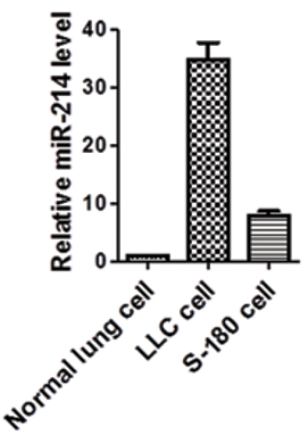

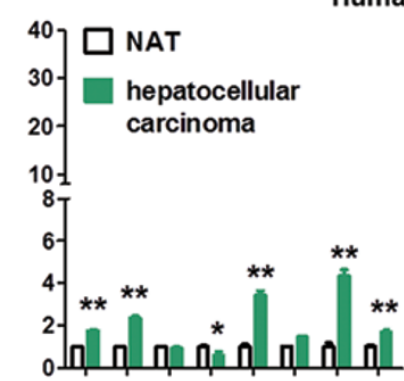
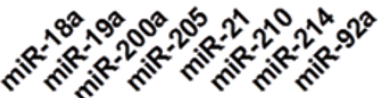

G S-180 implanted mouse plasma
Human tissue
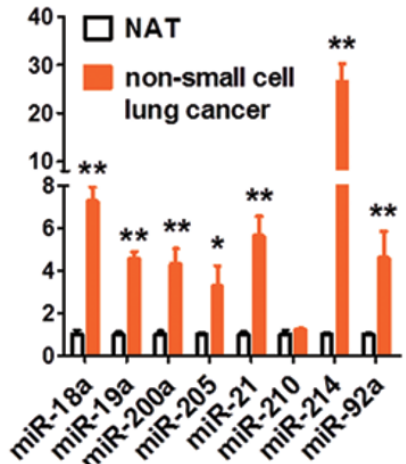
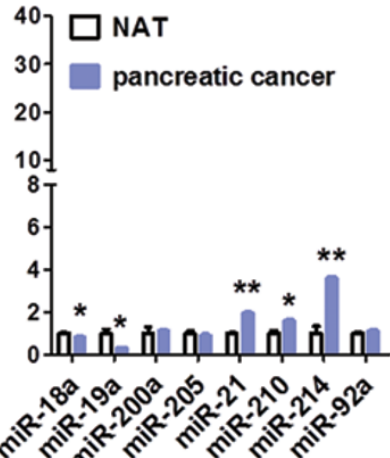

C

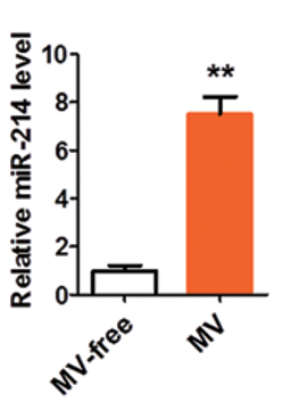

H

\section{LLC implanted mouse plasma}
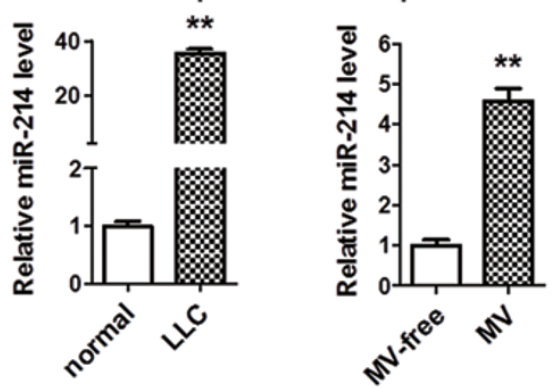

Figure 1 Increased miR-214 levels in cancer patients and mice implanted with tumors. (A, B) Elevated tumor-associated miRNAs in tissue and plasma samples from breast cancer, hepatocellular carcinoma, non-small-cell lung cancer, and pancreatic cancer patients. The miRNA expression levels were determined by qRT-PCR. The results are presented as the mean \pm SEM (tissue, $n=4$; plasma, $n=10$ ). NAT, normal adjacent tissues. (C, F, H) Comparison of the levels of miR-214 in the MV and MV-free fractions of plasma from the non-small-cell lung cancer patients and S-180- and LLC-implanted C57BL/6J mice. The expression levels of the miRNAs in the MV-free plasma were arbitrarily set to 1. (D) Comparison of the relative expression levels of miR-214 in normal lung cells, LLC cells, and S-180 cells. (E, G) Relative plasma miR-214 levels in C57BL/6J mice with or without the implantation of S-180 and LLC cells. The results are presented as the mean \pm SEM $(n=10)$. ${ }^{*} P<0.05$; ${ }^{* *} P<0.01$.

miR-199a-2 [21-23]. Consistent with previous studies $[24,25]$, we found that mature miR-199a and pre-miR$199 \mathrm{a}-2$ gradually increased in cultured $\mathrm{CD}^{+} \mathrm{T}$ cells
(Figure 2D and 2E), suggesting that endogenous miR214 levels increased in differentiated Tregs or activated $\mathrm{T}$ cells. However, the levels of mature miR-199a, pre- 
miR-199a-2, and Dnm3os were the same in untreated $\mathrm{CD}^{+} \mathrm{T}$ cells and $\mathrm{CD} 4^{+} \mathrm{T}$ cells treated with MVs (Figure $2 \mathrm{D}-2 \mathrm{~F}$ ), suggesting that endogenous miR-214 level was not boosted by the incubation with MVs. Taken together, these results indicate that exogenous miR-214 was sufficiently delivered into the recipient $\mathrm{T}$ cells and that the increase in miR-214 levels in $\mathrm{CD}^{+}{ }^{+} \mathrm{T}$ cells was not due to the induction of endogenous miR-214 by MVs.

Next, the effect of LLC-derived MVs on recipient T cells was assessed. As shown in Figure 2G, LLC-derived MVs significantly increased the percentage of $\mathrm{CD} 4{ }^{+} \mathrm{C}$ $\mathrm{D} 25^{\text {high }} \mathrm{Foxp} 3^{+}$Tregs. To confirm that the expansion of $\mathrm{CD} 4^{+} \mathrm{CD} 25^{\text {high }} \mathrm{Foxp}^{+}$Tregs was mainly due to exogenous miR-214 in MVs, miR-214-deficient LLC-derived
A

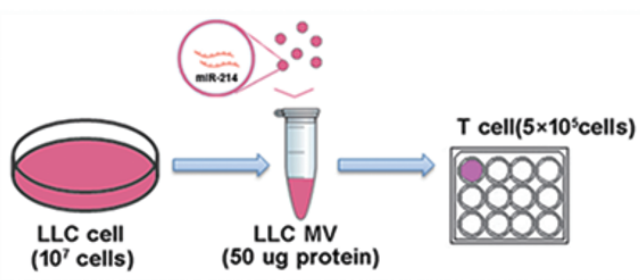

D

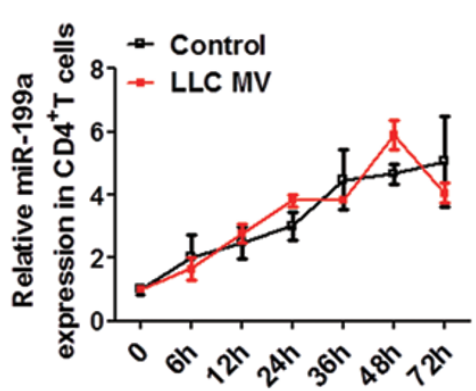

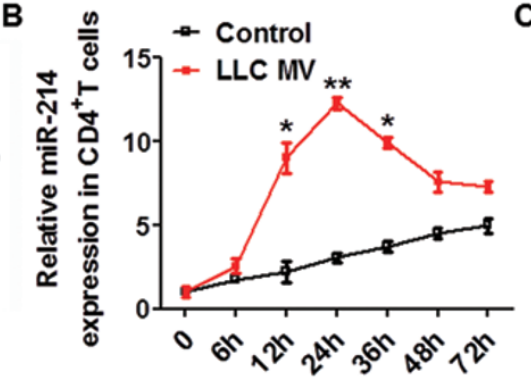

C

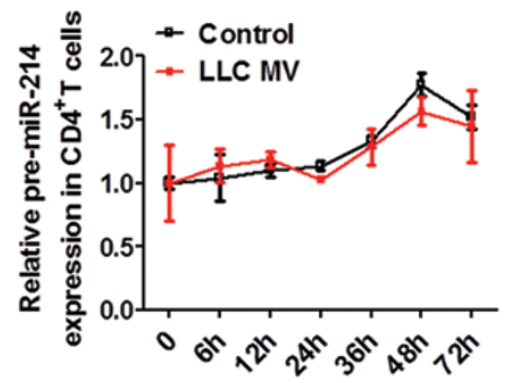

G

E

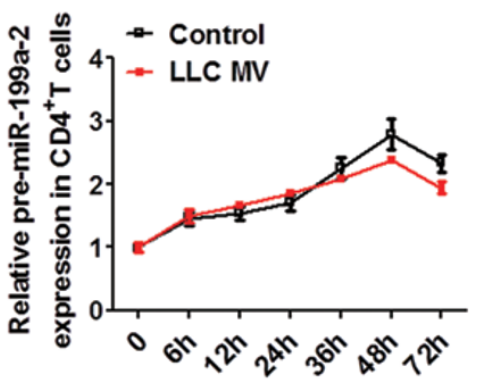

F

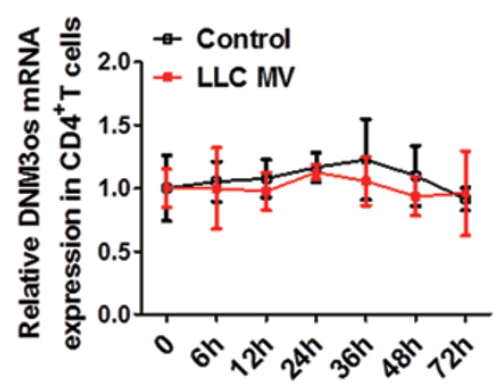

Gate:CD4+Tcells
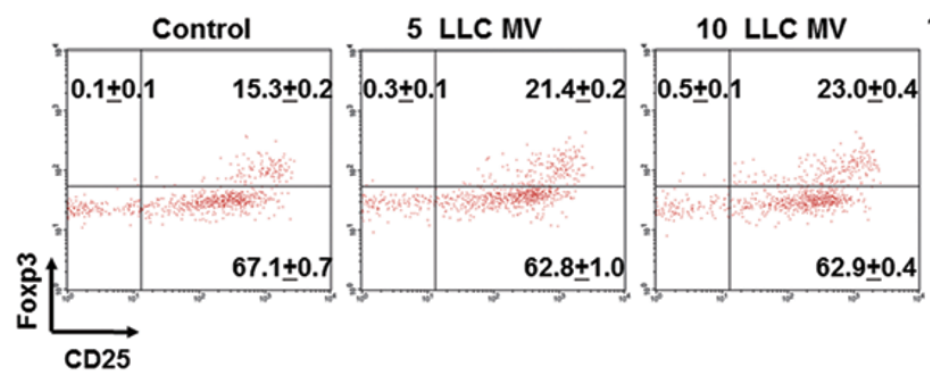

10 LLC MV/miR-214 def

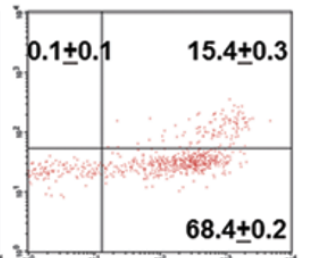

$68.4 \pm 0.2$

LLC MV/miR-214 def

( $\mu \mathrm{g}$

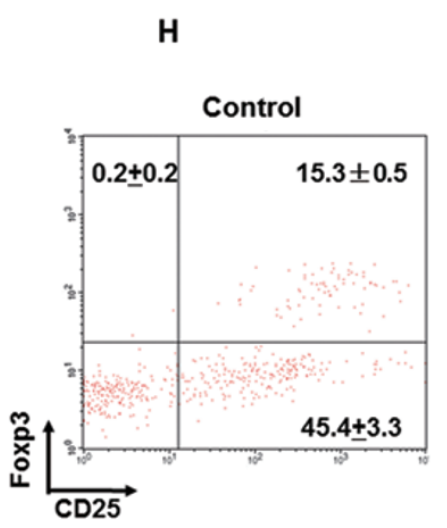

Gate:CD4+Tcells
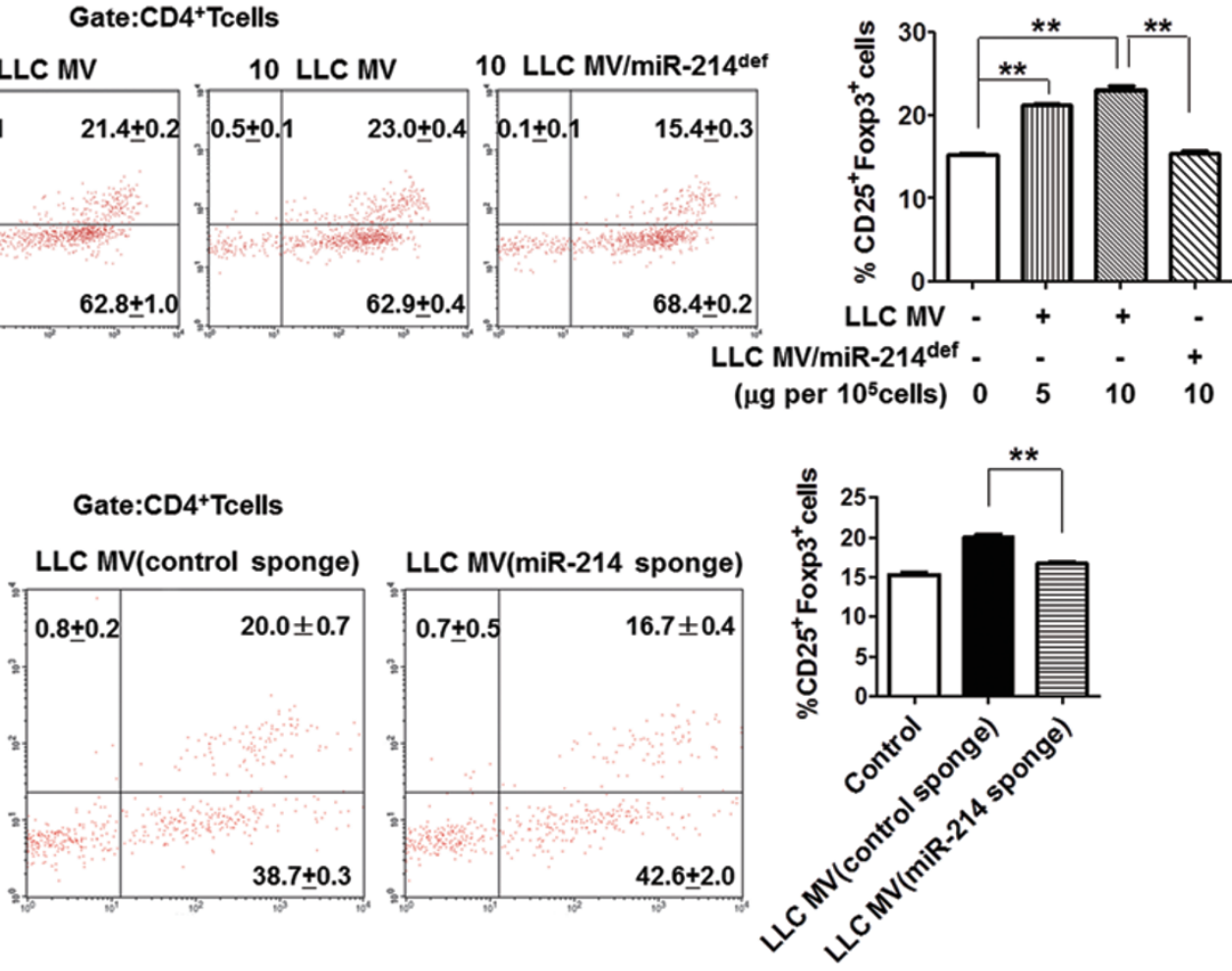
Figure 2 Effects of LLC MVs on miR-214 induction and Treg expansion in recipient CD4 ${ }^{+}$T cells. (A) Flow chart of the experimental design. The LLC MVs were isolated from LLC cells and were subjected to qRT-PCR to measure miR-214 level and the BCA method to quantify the total protein. According to our calculation, the amount of total protein in the LLC MVs isolated from $10^{7}$ LLC cells was $50 \mu \mathrm{g}$, and the level of miR-214 in these MVs was $3.125 \mathrm{fmol}$. Thus, miR-214 was present in the LLC MVs at a concentration of approximately $0.06 \mathrm{fmol} / \mu \mathrm{g}$ total protein. The LLC MVs were then incubated with $5 \times 10^{5}$ primary

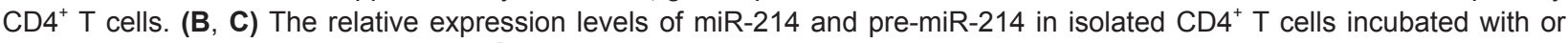
without the LLC MVs (10 $\mu \mathrm{g}$ protein $/ 10^{5} \mathrm{CD}^{+} \mathrm{T}$ cells) for $0,6,12,24,36,48$, and $72 \mathrm{~h}$. The miRNA expression levels were determined by qRT-PCR and are presented as the mean \pm SEM of three independent experiments. (D-F) The relative expression levels of mature miR-199a, pre-miR-199a-2, and Dnm3os in isolated CD4 ${ }^{+}$T cells incubated with or without LLC MVs (10 $\mu \mathrm{g}$ protein $/ 10^{5} \mathrm{CD} 4^{+} \mathrm{T}$ cells) for $0,6,12,24,36,48$, and $72 \mathrm{~h}$. The expression levels were determined by qRT-PCR and are presented as the mean \pm SEM of three independent experiments. (G) The induction of CD4 ${ }^{+} C D 25^{\text {high }}$ Foxp3 ${ }^{+}$Tregs in isolated $\mathrm{CD}^{+} \mathrm{T}$ cells after treatment with different concentrations of LLC MVs or miR-214-deficient LLC MVs (LLC MV/miR-214 ${ }^{\text {def }}$ ) for $72 \mathrm{~h}$. The left panels show a representative result of five experiments. The results from five independent experiments are plotted presented as the mean \pm SEM (right panel). $(\mathrm{H})$ The induction of CD4 ${ }^{+} \mathrm{CD} 25^{\text {high }} \mathrm{Foxp}^{+}$Tregs in isolated CD4 $^{+} \mathrm{T}$ cells after treatment with LLC MVs (control sponge) or miR-214-deficient LLC MVs (miR-214 sponge) for $72 \mathrm{~h}$. The left panels show a representative result of five experiments. The results from five independent experiments are plotted and presented as the mean \pm SEM (right panel). ${ }^{*} P<0.05 ;{ }^{* \star} P<0.01$.

MVs were prepared by knocking down miR-214 using antisense oligonucleotides (ASOs). The knockdown efficiency in the LLC cells is shown in Supplementary information, Figure S1A. Knockdown of miR-214 in the LLC cells resulted in the production of MVs containing low levels of miR-214 (Supplementary information, Figure 1B). miR-214-deficient MVs did not affect $\mathrm{CD} 4^{+} \mathrm{CD} 25^{\text {high }}$ Foxp $3^{+}$Treg expansion (Figure $2 \mathrm{G}$ ). The effects of miR-214 loss-of-function in MVs were further tested using "miRNA sponge" technology to produce miR-214-deficient LLC-derived MVs (Supplementary information, Figure 2A) [26]. The miR-214 sponge efficiently blocked the activity of miR-214 (Supplementary information, Figure S2B). Importantly, the miR-214 sponge was not transported into MVs (Supplementary information, Figure S2C) and significantly decreased miR-214 levels in MVs (Supplementary information, Figure S2D). As shown in Figure 2H, miR-214-deficient MVs produced by the miR-214 sponge failed to affect Treg expansion. The iTRAQ quantitative proteomic technique and mRNA/miRNA microarray analysis of MVs with or without miR-214 were also performed to further confirm that the effect of miR-214-deficient MV on Tregs was due to the absence of miR-214 rather than non-specific changes in MVs. Most of the proteins in the miR-214-deficient MVs displayed little, if any, alterations ( 433 proteins were altered by 0.5 -1-fold; 214 proteins were altered by 1-1.5-fold, and 7 proteins were altered by 1.5-2-fold) (Supplementary information, Figure S3A). Only 7 proteins displayed a greater than twofold reduction (Supplementary information, Figure S3A), but to our knowledge, these proteins do not affect Tregs (Supplementary information, Table S1). Likewise, the transfection of anti-miR-214 did not substantially alter
mRNA or miRNA levels in the LLC MVs, with the exception of miR-214 (Supplementary information, Figure S3B and S3C). Based on the negligible changes in protein, mRNA, and miRNA levels in the miR-214-deficient MVs, it is unlikely that the recipient Tregs would be altered. Taken together, these results indicate that LLC-secreted miR-214 in MVs was delivered into the recipient $\mathrm{CD} 4^{+} \mathrm{T}$ cells sufficiently and promoted Treg expansion.

Decreased PTEN by LLC-secreted miR-214 results in Treg expansion

miR-214 targets PTEN and downregulates the PTEN-mediated signaling cascade $[13,25,27]$. PTEN is a negative modulator of $\mathrm{CD} 4{ }^{+} \mathrm{CD} 25^{\text {high }} \mathrm{Foxp}^{+}$Treg homeostasis in vivo and expansion ex vivo [28]. Therefore, we hypothesized that LLC-secreted miR-214 in MVs promotes Treg expansion by targeting PTEN in $\mathrm{CD} 4^{+}$ $\mathrm{T}$ cells. To assess whether exogenous miR-214 in MVs was able to directly bind to the PTEN 3' UTR, luciferase reporter assays were performed (Supplementary information, Figure S4A and S4B). The activity of luciferase reporter containing the PTEN 3' UTR was significantly repressed upon treatment with LLC MV but not LLC $\mathrm{MV} / \mathrm{miR}-214^{\text {def }}$, whereas the mutant luciferase reporter activity was unaffected upon treatment with either LLC MV or LLC MV/miR-214 ${ }^{\text {def }}$ (Supplementary information, Figure S4C). Next, the effects of LLC-secreted miR-214 on PTEN levels in the recipient $\mathrm{CD}^{+} \mathrm{T}$ cells were assessed. Treatment with LLC MVs reduced PTEN protein levels in the $\mathrm{CD}^{+} \mathrm{T}$ cells in a dose-dependent manner (Figure 3A), whereas the levels of PTEN mRNA in the $\mathrm{CD} 4^{+} \mathrm{T}$ cells were unchanged (Supplementary information, Figure S5A). Interestingly, although miR-214 levels were markedly increased in the recipient $\mathrm{CD}^{+} \mathrm{T}$ 
A
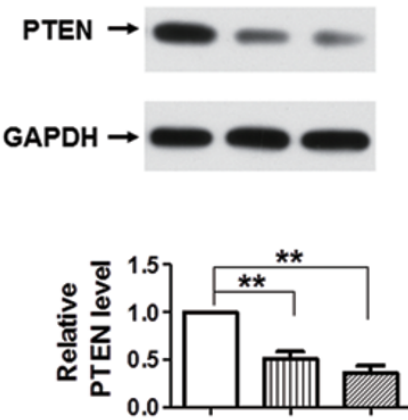

$\begin{array}{llll}\text { LLC MV } & 0 & 5 & 10\end{array}$ ( $\mu$ g per $10^{5}$ cells)

F

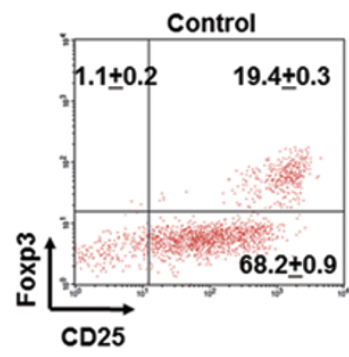

Gate:CD4 ${ }^{+}$Tcells

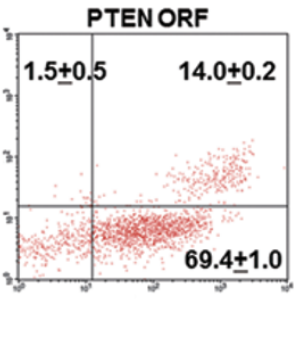

B
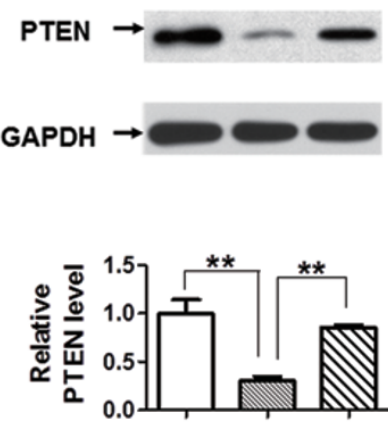

LLC MV

LLC MVI miR-214 def - - +
C

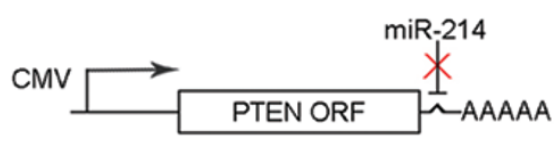

D

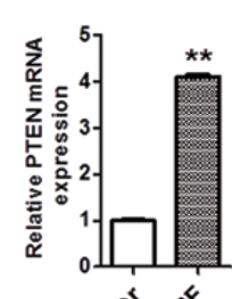

E

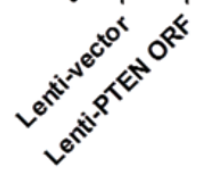

G
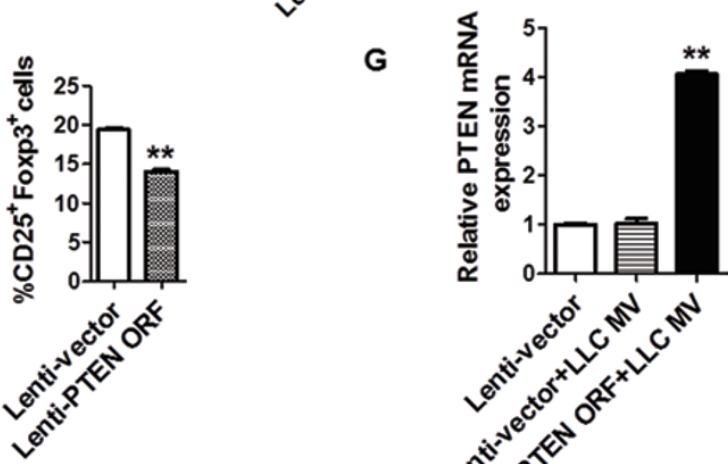

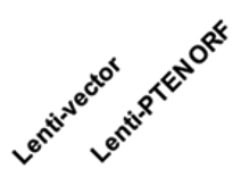

PTEN -

GAPDH $\longrightarrow$

H
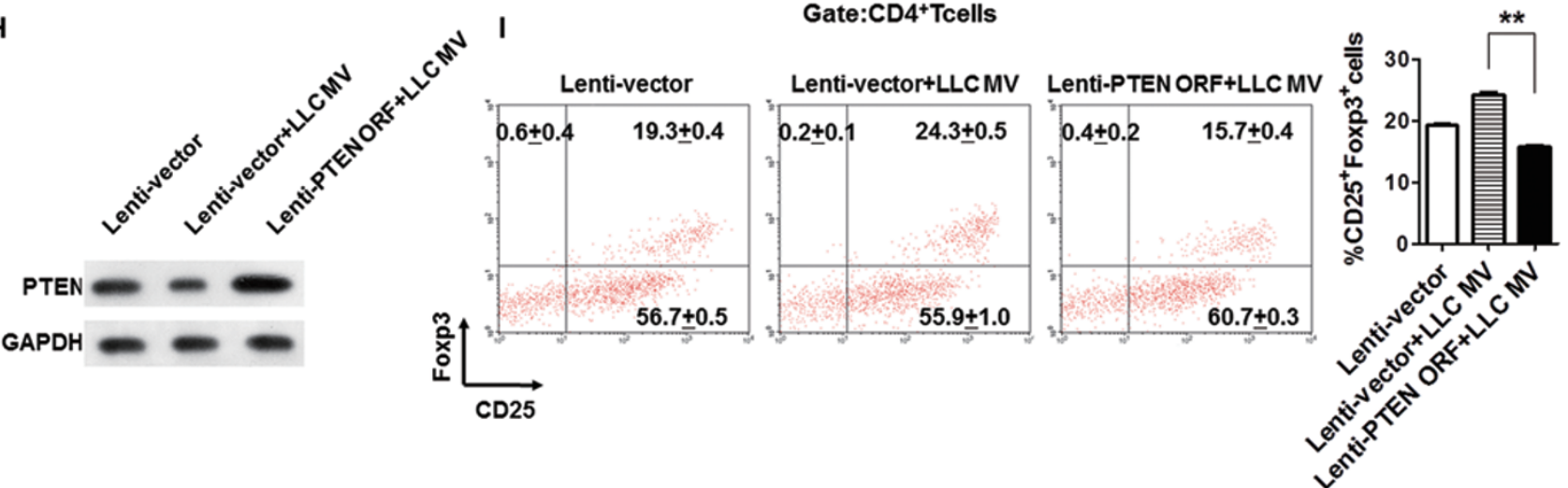

$\mathbf{J}$

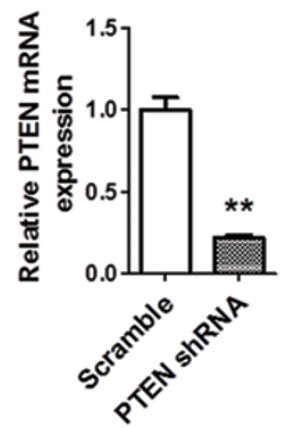

K

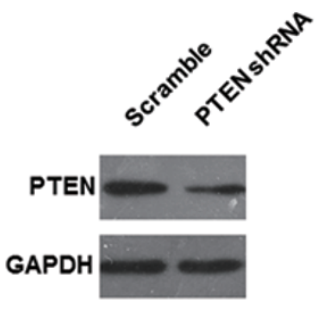

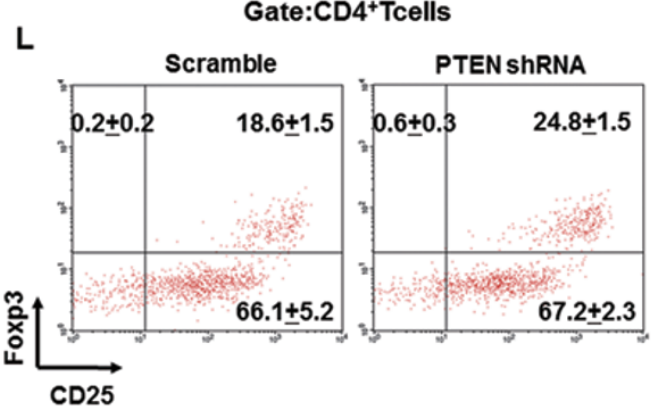

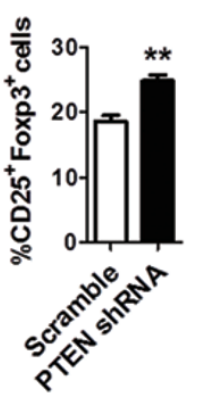


Figure 3 Effects of LLC-secreted miR-214 on PTEN suppression and Treg expansion in recipient CD4 ${ }^{+}$T cells. (A, B) Western blot analysis of PTEN protein levels in $\mathrm{CD}^{+} \mathrm{T}$ cells following incubation with different concentrations of LLC MVs $(0,5$, and $10 \mu \mathrm{g}$ protein $/ 10^{5}$ cells) (A) and miR-214-deficient LLC MVs (10 $\mu \mathrm{g}$ protein $/ 10^{5}$ cells) (B) for $72 \mathrm{~h}$. (C) A diagram of the recombinant lentivirus carrying the miR-214-resistant version of PTEN (PTEN ORF). (D, E) qRT-PCR and western blot analysis of PTEN mRNA and protein levels in $\mathrm{CD}^{+} \mathrm{T}$ cells following infection with a control or PTEN ORF-overexpressing lentivirus. (F) Induction of $\mathrm{CD}^{+}{ }^{+} \mathrm{CD} 25^{\text {high }}$ Foxp $3^{+}$Tregs in isolated $\mathrm{CD} 4^{+} \mathrm{T}$ cells after infection with a control or PTEN ORF-overexpressing lentivirus. The left panels show a representative result of five experiments. The results from five independent experiments are plotted and presented as the mean \pm SEM (right panel). (G, H) qRT-PCR and western blot analysis of PTEN mRNA and protein levels in $\mathrm{CD}^{+} \mathrm{T}$ cells following treatment with the control lentivirus, control lentivirus plus LLC MVs, or PTEN ORF-overexpressing lentivirus plus LLC MVs. (I) Induction of CD4 ${ }^{+} C D 25^{\text {high }}$ Foxp3 ${ }^{+}$Tregs in isolated CD4 ${ }^{+} \mathrm{T}_{\text {cells }}$ after treatment with the control lentivirus, control lentivirus plus LLC MVs, or PTEN ORF-overexpressing lentivirus plus LLC MVs. The left panels show a representative result of five experiments. The results from five independent experiments are presented as the mean \pm SEM (right panel). (J, K) qRT-PCR and western blot analysis of PTEN mRNA and protein levels in CD4 ${ }^{+}$T cells following infection with a lentiviral control or lentiviral shRNA targeting PTEN. (L) The induction of CD4 ${ }^{+}$CD2 $5^{\text {high }}$ Foxp3 ${ }^{+}$Tregs in isolated $\mathrm{CD}^{+} \mathrm{T}$ cells after infection with a lentiviral control or lentiviral shRNA targeting PTEN. The left panels show a representative result of five experiments. The results from five independent experiments are plotted and presented as the mean \pm SEM (right panel). ${ }^{*} P<0.05 ;{ }^{* *} P<0.01$.

cells and peaked $24 \mathrm{~h}$ post MV treatment (Figure 2B), the PTEN protein was consistently downregulated from 24 to $72 \mathrm{~h}$ post treatment (Supplementary information, Figure S5B), whereas no alterations in PTEN mRNA level were observed (Supplementary information, Figure $\mathrm{S} 5 \mathrm{C})$. These results further demonstrate that miR-214 affects PTEN at the protein rather than the mRNA level. By contrast, neither LLC MV/miR-214 ${ }^{\text {def }}$ (Figure 3B) nor "sponge"-produced miR-214-deficient MVs (Supplementary information, Figure S6A and S6B) affected PTEN protein levels. These data suggest that LLC-secreted miR-214 in MVs sufficiently reduces PTEN protein levels in recipient $\mathrm{CD}^{+} \mathrm{T}$ cells.

To determine whether the effect of LLC-secreted miR214 on Treg expansion is dependent on PTEN silencing, $\mathrm{T}$ cells were infected with a recombinant lentivirus carrying the miR-214-resistant form of PTEN (PTEN ORF) (Figure 3C). Efficient overexpression of the PTEN ORF in $\mathrm{CD}^{+} \mathrm{T}$ cells is shown in Figure $3 \mathrm{D}$ and $3 \mathrm{E}$. The overexpression of PTEN potently suppressed Treg expansion (Figure 3F). Although the LLC MVs downregulated PTEN protein levels in $\mathrm{CD}^{+} \mathrm{T}$ cells, overexpression of PTEN ORF rescued the downregulation of PTEN protein induced by the miR-214-loaded MVs (Figure 3G and $3 \mathrm{H}$ ). Consistent with these results, the $\mathrm{T}$ cells treated with the LLC MVs had a significantly higher proportion of Tregs compared with the control cells, but the cells treated with both the LLC MVs and PTEN ORF-overexpressing lentivirus exhibited significantly lower levels of Tregs (Figure 3I), suggesting that the miR-214-resistant PTEN compromised miR-214-induced Treg conversion. Moreover, a lentiviral shRNA was used to directly knock down PTEN expression in $\mathrm{CD}^{+} \mathrm{T}$ cells. Efficient knockdown of PTEN in $\mathrm{CD}^{+} \mathrm{T}$ cells is shown in Figure 3J and $3 \mathrm{~K}$. As expected, the inhibition of PTEN expression potently promoted Treg expansion (Figure 3L).

Finally, to mimic the effects of miRNA secretion on recipient $\mathrm{CD}^{+} \mathrm{T}$ cell function in vivo, a transwell system was used in which secreted miR-214 crossed an insert to regulate PTEN expression and Treg expansion (Supplementary information, Figure S7A). CD4 ${ }^{+} \mathrm{T}$ cells co-cultured with the miR-214-deficient LLC cells had decreased levels of miR-214 and increased levels of PTEN protein compared with $\mathrm{CD} 4^{+} \mathrm{T}$ cells co-cultured with LLC cells (Supplementary information, Figure S7BS7D). Consistent with these results, there was a significant decrease in the percentage of Tregs in the $\mathrm{CD} 4^{+} \mathrm{T}$ cells co-cultured with the miR-214-deficient LLC cells compared to the $\mathrm{CD}^{+} \mathrm{T}$ cells co-cultured with LLC cells (Supplementary information, Figure S7E). Taken together, LLC-secreted miR-214 targets PTEN in $\mathrm{CD}^{+} \mathrm{T}$ cells, leading to Treg expansion.

Exogenous miR-214 induces IL-10 secretion in $C D 4^{+} T$ cells and promotes xenograft tumor growth in nude mice

To monitor the functions of the induced Tregs, the levels of several cytokines [2,5] associated with Tregs were measured in the culture supernatants of $\mathrm{CD} 4^{+} \mathrm{T}$ cells treated with or without the LLC MVs. Treatment with LLC MVs significantly increased the levels of interleukin-10 (IL-10) but not TGF- $\beta$ or interleukin-12 (IL-12), and depletion of miR-214 from the LLC MVs significantly blocked IL-10 production (Figure 4A-4C). These results suggest that IL-10 might be involved in the suppression of the immune system by Tregs induced by tumor-secreted miR-214.

The functional activity of the Tregs induced by tumor-secreted miR-214 was further tested in nude mice. As depicted in Figure 4D, murine $\mathrm{CD}^{+} \mathrm{T}$ cells were pretreated with or without LLC MVs and then injected 
A

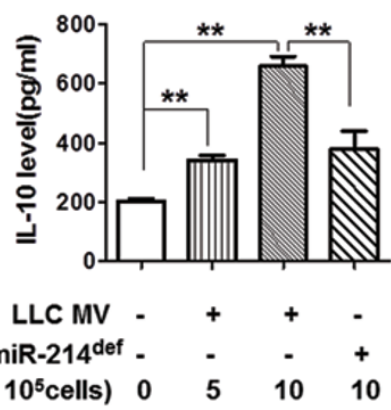

B

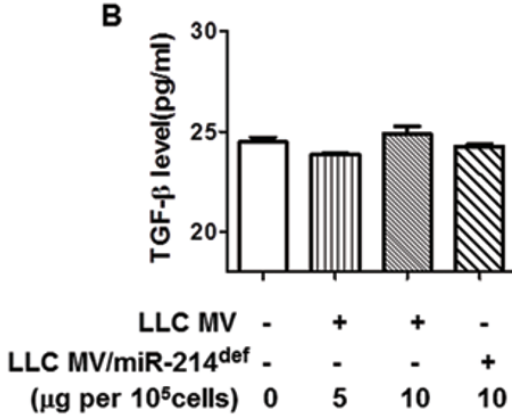

C
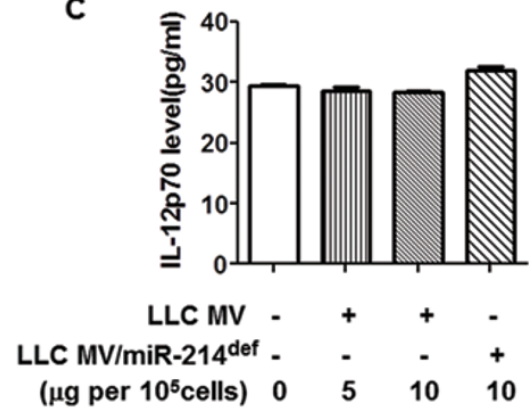

D

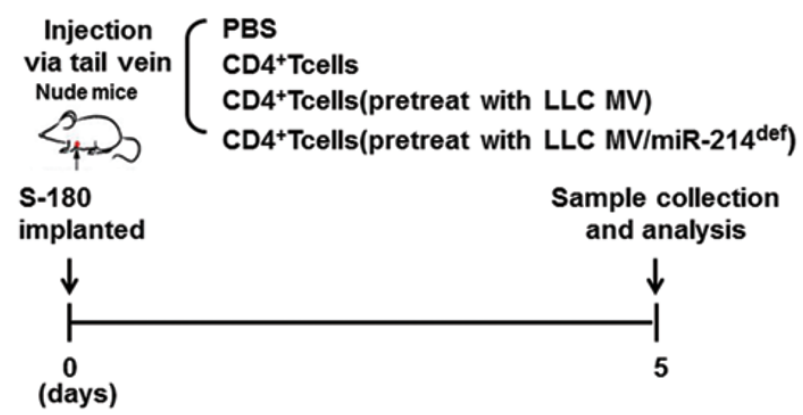

E

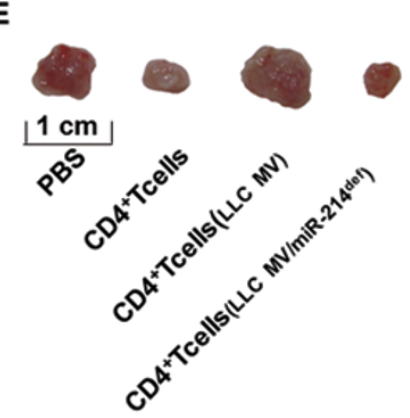

$\mathbf{F}$

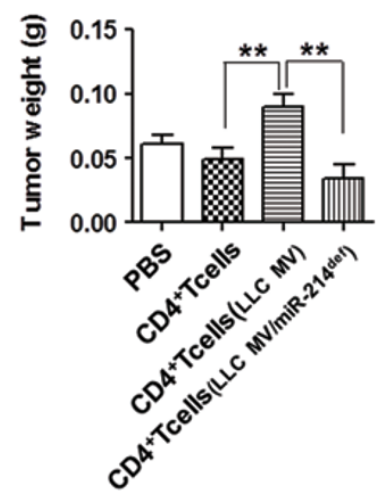

Figure 4 Effects of LLC-secreted miR-214 on cytokine secretion in CD4 ${ }^{+}$T cells and tumor growth in nude mice. (A-C) ELISA analysis of IL-10, TGF- $\beta$, and IL-12 levels in the supernatants of CD4 ${ }^{+}$T cells incubated with different concentrations of the LLC MVs or miR-214-deficient LLC MVs for 72 h. (D) Flow chart depicting the experimental design. Isolated murine CD4 ${ }^{+}$ cells, CD4 ${ }^{+} \mathrm{T}$ cells pretreated with LLC MVs $\left(10 \mu \mathrm{g}\right.$ protein $/ 10^{5} \mathrm{CD} 4^{+} \mathrm{T}$ cells), CD4 ${ }^{+} \mathrm{T}$ cells pretreated with LLC MVs depleted of miR-214 (10 $\mu \mathrm{g}$ protein $/ 10^{5} \mathrm{CD} 4^{+} \mathrm{T}$ cells), or a saline control were administered to nude mice via tail vein injection $\left(5 \times 10^{6}\right.$ cells), and sarcoma S-180 cells $\left(1 \times 10^{6}\right.$ cells per mouse) were implanted. (E) Tumor size. (F) Tumor burden. The data are presented as the mean \pm SEM of three independent experiments. In each experiment, each group consisted of 6-8 mice. ${ }^{*} P$ $<0.05 ;{ }^{* *} P<0.01$.

into nude mice via the tail vein. The nude mice were also implanted with S-180 cells. The Tregs induced by tumor-secreted miR-214 strongly promoted tumor growth in the nude mice (Figure 4E and $4 \mathrm{~F}$ ), suggesting that miR-214-induced Tregs can effectively suppress the immune responses of tumor-attacking cytotoxic cells, such as natural killer (NK) cells and macrophages.

Cancer cell-secreted miR-214 is sufficiently delivered into $C D 4^{+}$T cells in vivo

Two approaches were performed to directly monitor the transport of miR-214 into peripheral $\mathrm{CD}^{+} \mathrm{T}$ cells via tumor-derived MVs. First, LLC MVs were fluorescently labeled and then intravenously injected into mice. A significant amount of fluorescent MVs were associated with the peripheral $\mathrm{CD}^{+} \mathrm{T}$ cells $1 \mathrm{~h}$ after injection (Figure 5A). In the second approach, the miR-214 ${ }^{\text {mut }}$ (mimic of miR-214) was tracked. miR-214 ${ }^{\text {mut }}$ could be distinguished from miR-214 by using specific probes and primers in qRT-PCR assay. miR-214 ${ }^{\text {mut }}$ was transfected into LLC cells, and the miR-214 ${ }^{\text {mut }}$-containing LLC MVs were collected and intravenously injected into C57BL/6J mice. The peripheral $\mathrm{CD}^{+} \mathrm{T}$ cells isolated from these mice contained a significant amount of miR-214 ${ }^{\text {mut }}$ (Figure $5 \mathrm{~B}$ and $5 \mathrm{C}$ ), and miR-214 ${ }^{\text {mut }}$ levels were markedly increased in the plasma and peaked 30 min post injection (Figure 5D). The miR-214 ${ }^{\text {mut }}$-transfected tumor cells were also directly injected into the mice. When the mice were directly implanted with $10^{6} \mathrm{miR}-214^{\mathrm{mut}}$-transfected tumor cells, miR-214 ${ }^{\text {mut }}$ was readily detected in the isolated $\mathrm{CD}^{+} \mathrm{T}$ cells (Figure 5E). Taken together, these results demonstrate that cancer cell-secreted miR-214 may be delivered into peripheral $\mathrm{CD}^{+} \mathrm{T}$ cells via MVs.

Cancer cell-secreted miR-214 increases the number of Tregs and promotes tumor growth in vivo

We next determined the effects of secreted miR-214 on Tregs and tumor growth in vivo. Mice were given 
A
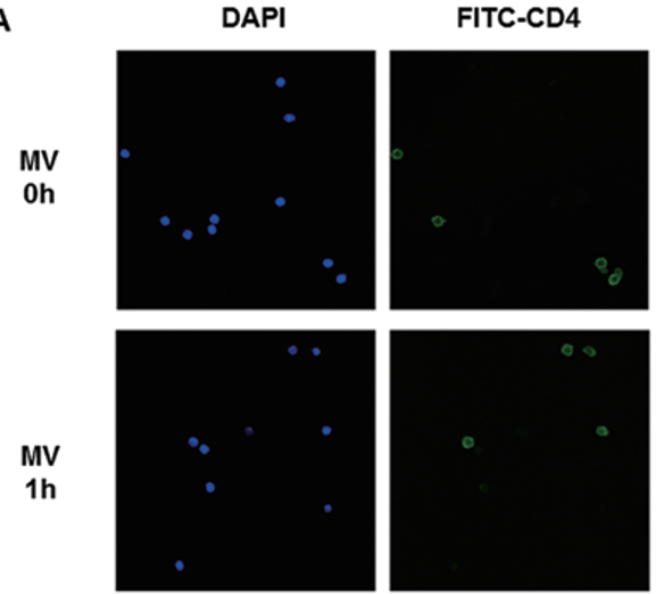

D

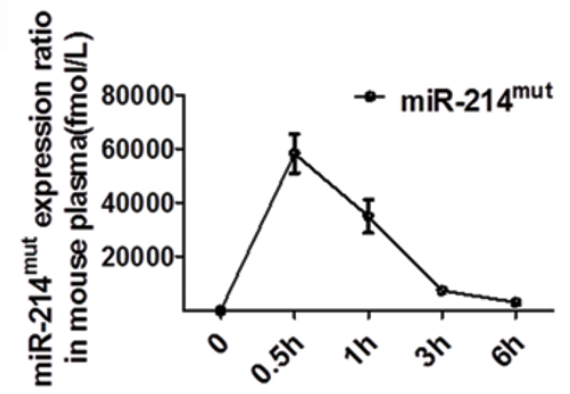

FITC-CD4
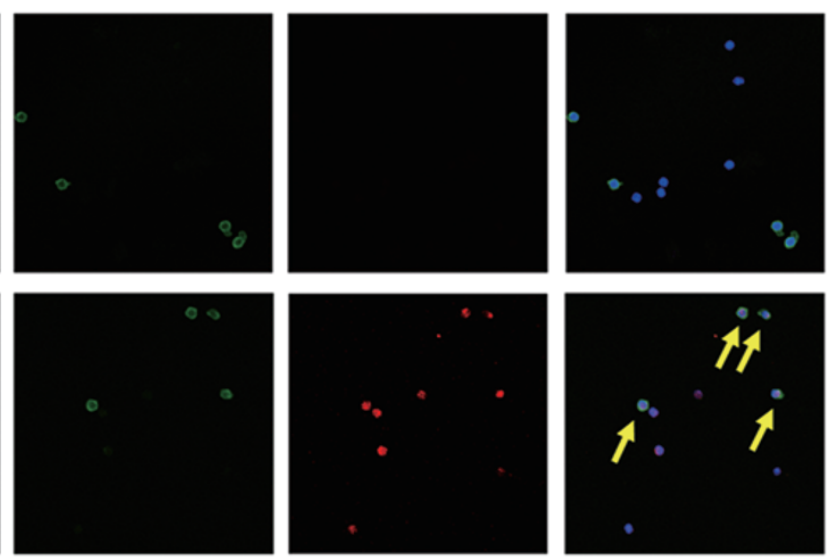

E
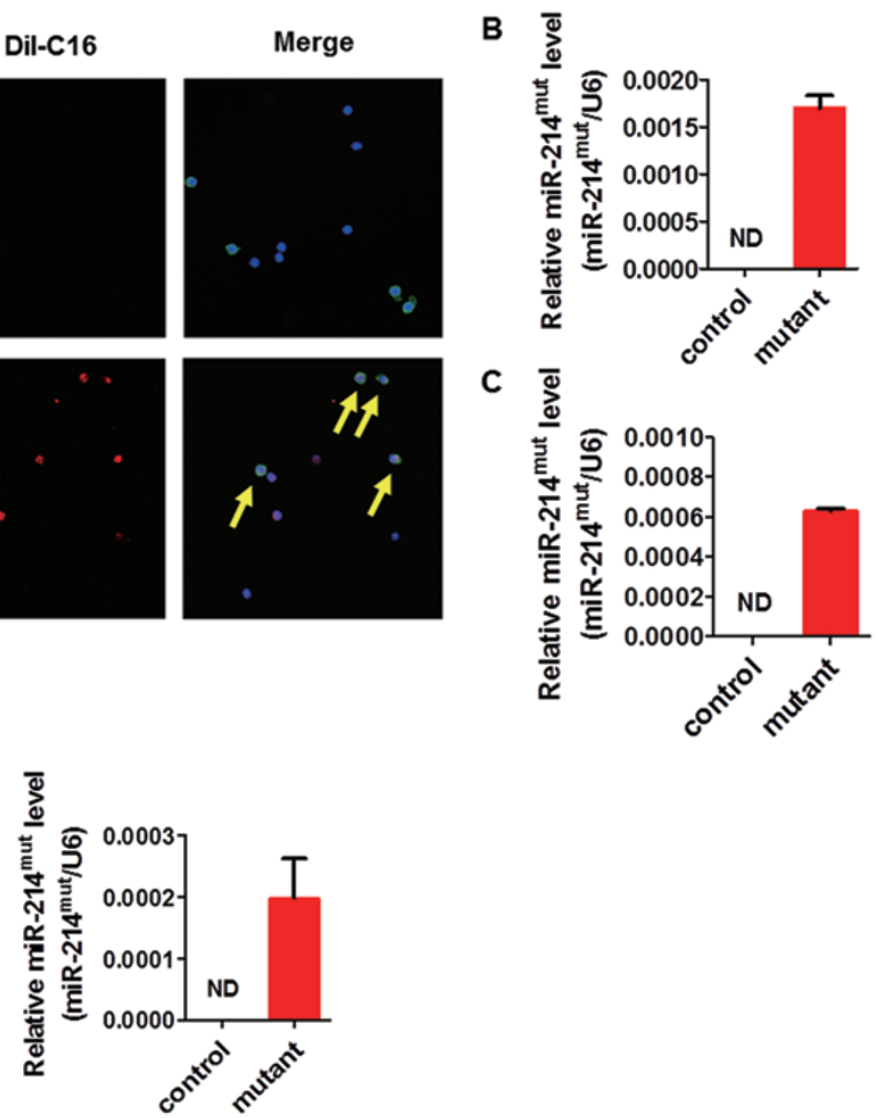

Figure 5 LLC-derived MV sufficiently delivers exogenous miR-214 into the recipient CD4 ${ }^{+} \mathrm{T}$ cells in vivo. (A) Confocal microscopy image of the internalization of fluorescently labeled MVs in peripheral CD4 ${ }^{+} \mathrm{T}$ cells. A total of $100 \mu \mathrm{g}$ of the DilC18(3)-labeled LLC MVs was injected into each C57BL/6J mouse via the tail vein. After $1 \mathrm{~h}$, the peripheral lymphocytes were incubated with FITC-conjugated anti-CD4 ${ }^{+}$antibody and DAPI, and the cells were washed, fixed, and observed by confocal microscopy. (B, C) Either 600 or 0.6 pmol miR-214 ${ }^{\text {mut }}$ (ACAGCAGGAACAGUCAGCCAAU) was transfected into $10^{7}$ LLC cells, and the miR-214 ${ }^{\text {mut }}$-containing LLC MVs were collected and injected into C57BL/6J mice via the tail vein. After $1 \mathrm{~h}$, the peripheral $\mathrm{CD} 4^{+} \mathrm{T}$ cells were isolated and assayed for miR-214 ${ }^{\mathrm{mut}}$ using TaqMan probes specifically designed for miR-214 ${ }^{\mathrm{mut}}$. (D) A total of 600 pmol of miR-214 ${ }^{\text {mut }}$ was transfected into $10^{7}$ LLC cells, and the miR-214 ${ }^{\text {mut }}$-containing LLC MVs were injected into the C57BL/6J mice. The miR-214 ${ }^{\text {mut }}$ levels in the plasma of the C57BL/6J mice were assayed at $0,0.5,1,3$, and $6 \mathrm{~h}$ post injection. (E) A total of $0.6 \mathrm{pmol}$ miR-214 ${ }^{\text {mut }}$ was transfected into $10^{7}$ LLC cells, and the miR-214 ${ }^{\text {mut }}$-transfected tumor cells were implanted into the C57BL/6J mice $\left(10^{6}\right.$ per mouse). After 5 days, the peripheral CD4 ${ }^{+} \mathrm{T}$ cells were isolated and assayed for miR-214 ${ }^{\text {mut }}$. The results are presented as the mean \pm SEM of three independent experiments. ${ }^{*} P<0.05$; ${ }^{* \star} P<0.01$.

seven injections of LLC MVs over a span of 2 weeks (Supplementary information, Figure S8A). Consistent with findings in cancer patients and tumor-implanted mice (Figure 1), miR-214 levels in the plasma (Supplementary information, Figure S8B) and peripheral CD4 $\mathrm{T}$ cells (Supplementary information, Figure S8C) of LLC MV-injected mice were significantly higher compared with those in saline-injected mice. However, the levels of pre-miR-214 (Supplementary information, Figure S8D), as well as miR-199a, pre-miR-199a-2, and Dnm3os (Supplementary information, Figure S8E-S8G), in the peripheral $\mathrm{CD}^{+} \mathrm{T}$ cells did not change. These results con- firmed the transfer of exogenous miR-214 into the CD4 ${ }^{+}$ $\mathrm{T}$ cells. Following LLC MV treatment, the percentage of $\mathrm{CD} 4^{+} \mathrm{CD} 25^{\text {high }} \mathrm{Foxp}^{+}$Tregs in the peripheral and splenic $\mathrm{CD}^{+} \mathrm{T}$ cells increased from $3.2 \%$ and $7.8 \%$ to $5.5 \%$ and $12.7 \%$, respectively (Supplementary information, Figure S8H and S8I). C57BL/6J mice were also directly implanted with S-180 sarcoma cells (Supplementary information, Figure S9A). As expected, the percentage of $\mathrm{CD} 4^{+} \mathrm{CD} 25^{\text {high }} \mathrm{Foxp}^{+}$Tregs in the total $\mathrm{CD}^{+} \mathrm{T}$ cell population isolated from the peripheral blood and spleen was significantly higher in the tumor-implanted mice than the control mice (Supplementary information, Figure S9B). 
miR-214 levels were also increased in peripheral CD4 ${ }^{+} \mathrm{T}$ cells (Supplementary information, Figure S9C), whereas there was no change in pre-miR-214 levels (Supplementary information, Figure S9D), suggesting that the elevated miR-214 levels in the $\mathrm{CD}^{+}{ }^{+} \mathrm{T}$ cells were likely due to cancer cell secretion. Consistent with the results in tumor-implanted mice, the percentage of $\mathrm{CD} 4{ }^{+} \mathrm{CD} 25^{\text {high- }}$ Foxp $3^{+}$Tregs was higher in peripheral blood from lung cancer patients than that from normal subjects (Supplementary information, Figure S9E). Likewise, the level of miR-214 was significantly higher in plasma from lung cancer patients than that from normal subjects (Supplementary information, Figure S9F). We next examined the effect of LLC MVs on the growth of xenograft tumors. As depicted in Supplementary information, Figure S10A, C57BL/6J mice were pre-treated with or without LLC MVs and implanted with mouse sarcoma S-180 cells. When the mice were implanted with $10^{6} \mathrm{~S}-180$ cells, the plasma miR-214 levels were more than 20-fold higher in the LLC MV-pretreated mice compared with their control counterparts (Supplementary information, Figure S10B). Consistent with previous findings, the expansion of the Tregs compromised the immune response to the tumors, and the growth of the implanted tumors was significantly more rapid in the LLC MV-pretreated mice (Supplementary information, Figure S10C, left panel; Figure S10D, upper panel). Interestingly, when the mice were implanted with $10^{5} \mathrm{~S}-180$ cells, there was no tumor growth in the control mouse group, whereas successful tumor implantation and rapid tumor growth occurred in the LLC MV-pretreated mice (Supplementary information, Figure S10C, right panel; Figure S10D, lower panel). The tumor weight in the LLC MV-pretreated mice was also significantly higher than that in the control group (Supplementary information, Figure S10E).

Next, we confirmed the effects of tumor-secreted miR-214 on Treg expansion and tumor growth in vivo by comparing tumor-derived MVs with MVs released from 293T cells [18]. Both the 293T cells and 293T MVs contained low levels of miR-214 (Supplementary information, Figure S11A and S11B). The overexpression of miR-214 in 293T cells (Supplementary information, Figure S11C) resulted in the production of MVs containing high levels of miR-214 (Supplementary information, Figure S11D). Transfection of pre-miR-214 in 293T cells did not substantially affect the protein, mRNA, and miRNA levels in the 293T MVs, with the exception of miR214 (Supplementary information, Figure S11E-S11G). Various MVs from 293T and LLC cells were then used to pretreat mice, as depicted in Figure 6A. The LLC MV-induced downregulation of PTEN expression in mouse peripheral $\mathrm{CD}^{+} \mathrm{T}$ cells was reversed after the depletion of miR-214 from the LLC MVs (Figure 6B). In addition, although the control 293T MVs did not affect $\mathrm{CD}^{+} \mathrm{T}$ cell PTEN expression, the "modified" 293T MVs, which contained high levels of miR-214, resulted in the downregulation of PTEN expression in $\mathrm{CD}^{+} \mathrm{T}$ cells (Figure 6B). Compared with the control 293T MVs, which did not affect the expansion of $\mathrm{CD} 4^{+} \mathrm{CD} 25^{\text {high }} \mathrm{Foxp} 3^{+}$Tregs, LLC MVs and "modified" 293T MVs with high miR214 levels significantly increased the percentage of Tregs in peripheral and splenic $\mathrm{CD}^{+} \mathrm{T}$ cells (Figure 6C and 6D). This induction of Tregs by LLC MVs, however, was largely inhibited by the removal of miR-214 from the LLC MVs (Figure 6C and 6D). Consistent with this result, the growth of the implanted sarcoma in the LLC MV-treated mice was significantly faster than that in the saline- or normal 293T MV-treated control mice (Figure $6 \mathrm{E}$ and $6 \mathrm{~F}$ ). The enhancement of tumor growth following LLC MV treatment was inhibited by the depletion of miR-214 from the LLC MVs (Figure 6E and 6F). As expected, the "modified" 293T MVs with high miR-214 levels were able to promote tumor growth (Figure 6E and $6 \mathrm{~F})$.

To determine whether the observed pro-tumor effects of the tumor-derived MVs were truly Treg-dependent, inducible Treg-deficient mice (diphtheria toxin-treated Foxp $3^{\text {DTR }}$ mice) $[29,30]$ were treated with tumor-derived MVs (Supplementary information, Figure S12A). Our results indicated that the levels of miR-214 in peripheral $\mathrm{CD} 4^{+} \mathrm{T}$ cells of Foxp $3^{\text {DTR }}$ mice and wild-type Foxp $3^{+}$ littermates were significantly increased after LLC MV injection, whereas the levels of miR-214 were unchanged in mice injected with LLC MV/miR-214 ${ }^{\text {def }}$ (Supplementary information, Figure S12B). Wild-type Foxp $3^{+}$mice treated with LLC MVs had a higher percentage of Tregs in peripheral $\mathrm{CD}^{+} \mathrm{T}$ cells compared to wild-type Foxp $3^{+}$ mice treated with LLC MV/miR-214 ${ }^{\text {def }}$ (Supplementary information, Figure S12C). However, neither the LLC MVs nor LLC MV/miR-214 ${ }^{\text {def }}$ affected Treg levels in the Foxp $3^{\text {DTR }}$ mice (Supplementary information, Figure $\mathrm{S} 12 \mathrm{C})$. The growth rate of the implanted sarcoma in the LLC MV-treated Foxp $3^{+}$mice was significantly faster than that in the LLC MV/miR-214 ${ }^{\text {def }}$-treated Foxp $3^{+}$mice (Supplementary information, Figure S12D and S12E). In contrast, neither LLC MVs nor LLC MV/miR-214 ${ }^{\text {def }}$ promoted tumor growth in Foxp $3^{\text {DTR }}$ mice (Supplementary information, Figure S12F and S12G). Importantly, Treg elimination in the adult Foxp $3^{\text {DTR }}$ mice resulted in a more rapid development of terminal autoimmune disease compared with the Foxp $3^{+}$mice. In addition, several Foxp$3^{\text {DTR }}$ mice became moribund. However, the MV treatment did not affect the death rate in the Foxp $3^{\text {DTR }}$ mice (Supplementary information, Figure $\mathrm{S} 12 \mathrm{H}$ ). 
A

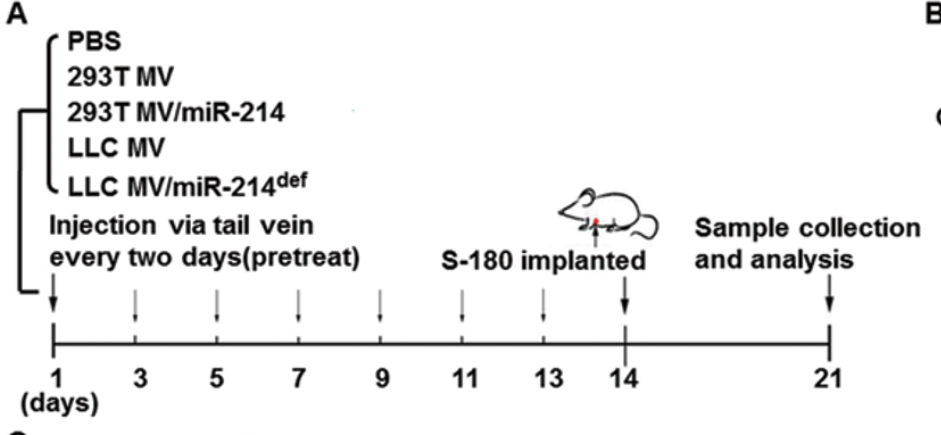

C
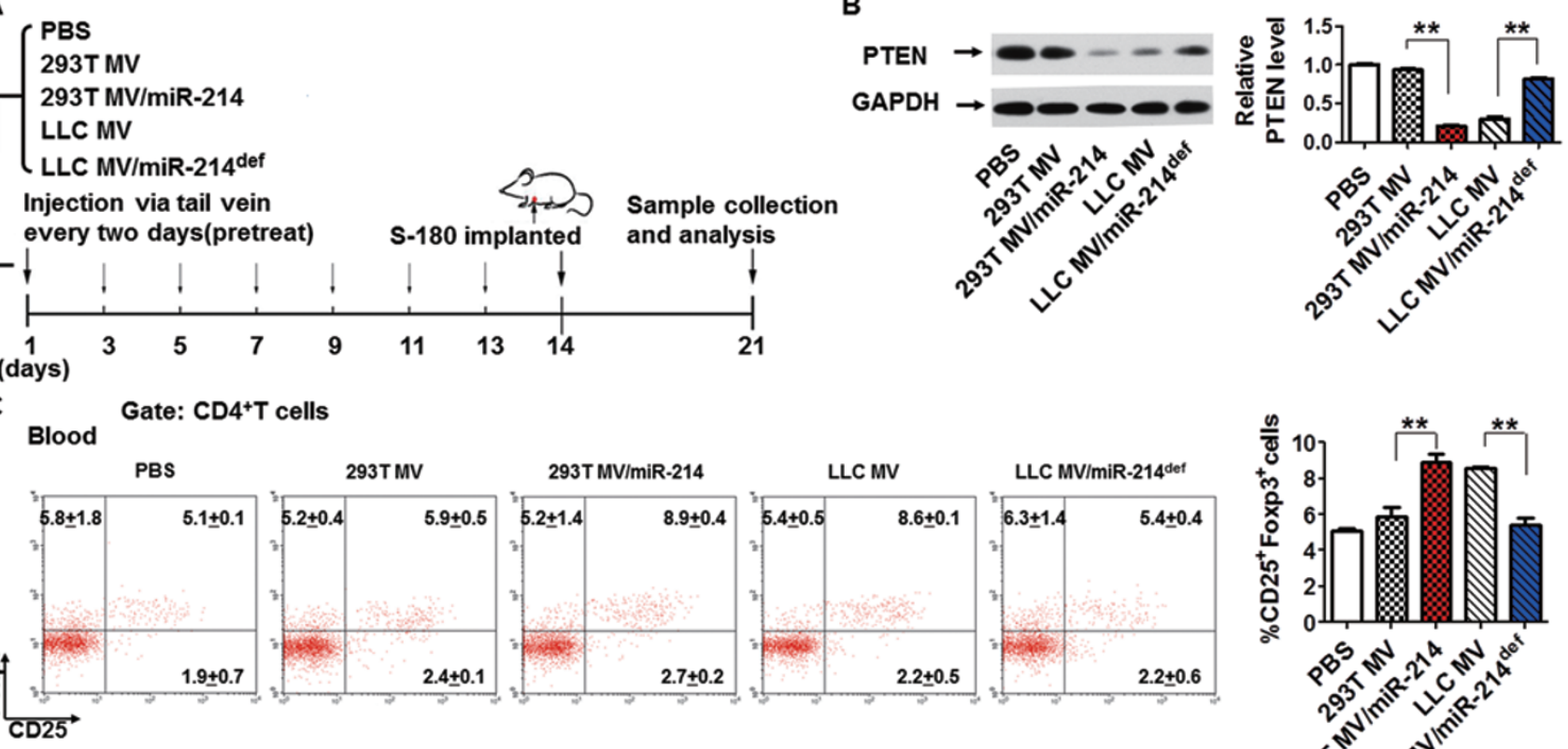

D
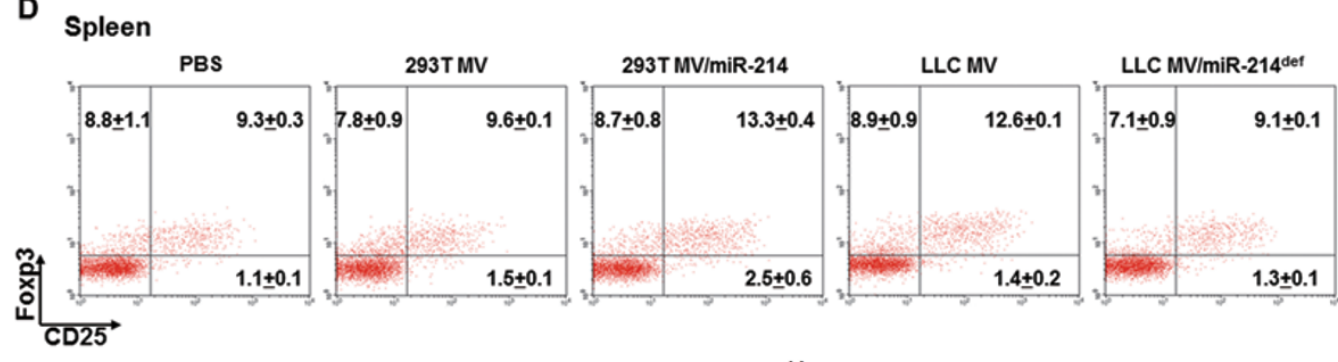

E

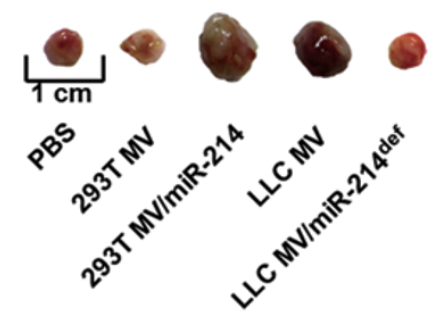

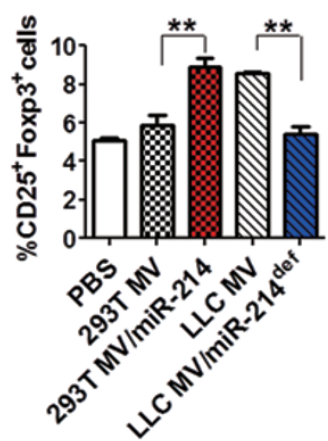

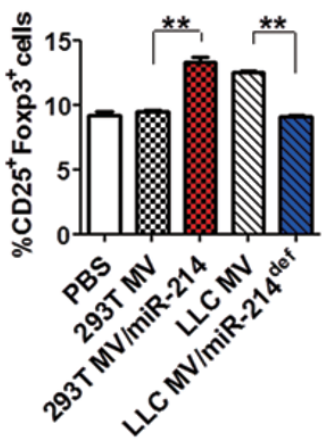

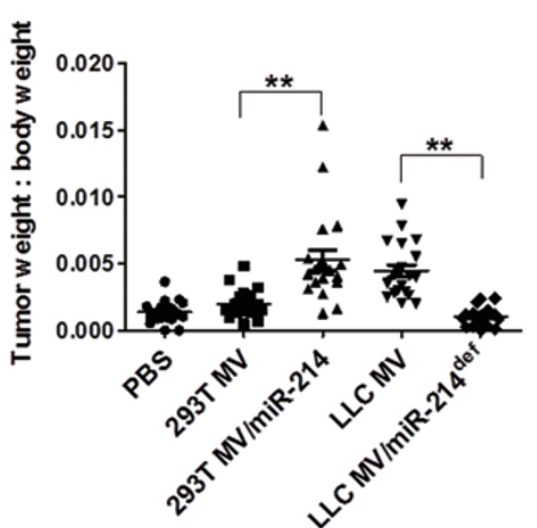

Figure 6 Effects of tumor-secreted miR-214 on CD4 ${ }^{+}$T cell PTEN expression, Treg induction, and tumor growth in C57BL/6J mice. (A) Flow chart of the experimental design. C57BL/6J mice were inoculated via the tail vein with saline (control) or MVs from normal 293T cells, 293T cells overexpressing miR-214, normal LLC cells, or LLC cells depleted of miR-214. The MVs were administered once every 2 days for 2 weeks (MV with $20 \mu \mathrm{g}$ of total protein in $100 \mu \mathrm{l}$ of PBS per mouse). The mice were then implanted with an S-180 sarcoma cells $\left(10^{6}\right.$ cells per mouse) and sacrificed after 7 days. (B) Western blot analysis of PTEN protein levels in CD4 ${ }^{+} \mathrm{T}$ cells from the mouse spleen. (C, D) Flow cytometric analysis of the population of Tregs in mouse whole blood (C) and spleen (D). (E, F) Tumor growth in mice treated with various types of MVs. The data are presented as the mean \pm SEM of three independent experiments. A total of six to eight mice were used in each group for each experiment. ${ }^{*} P<0.05$; ${ }^{* *} P<0.01$. 
Blocking of cancer cell-secreted miR-214 downmodulates Treg induction and reduces tumor growth

Because tumor-secreted miR-214 promotes the expan- sion of Tregs and the growth of implanted cancer cells, we determined whether the downregulation of circulating miR-214 levels could decrease the numbers of Tregs and

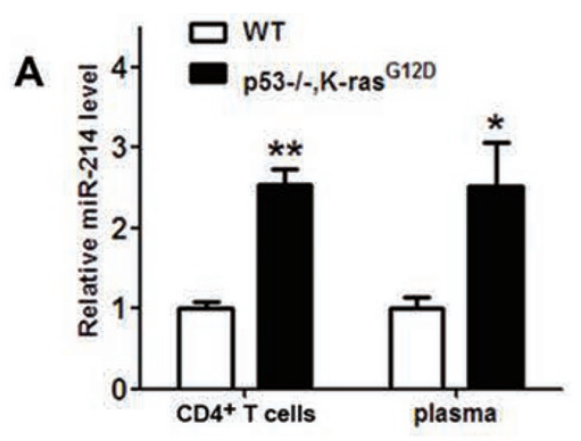

B

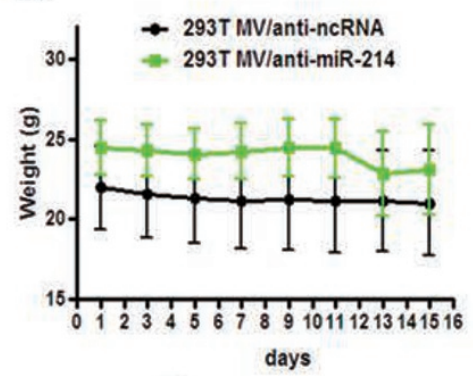

D 293T MVlanti-ncRNA

293T MVlant-miR-214

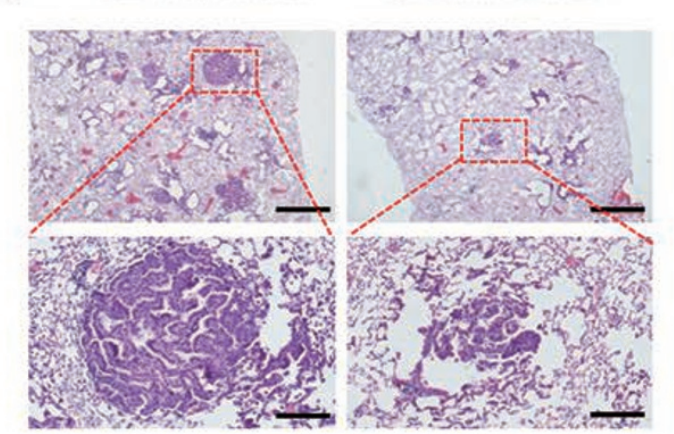

$\mathbf{E}$

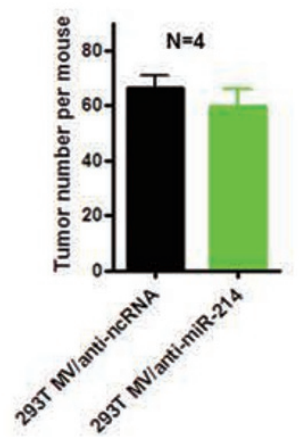

C

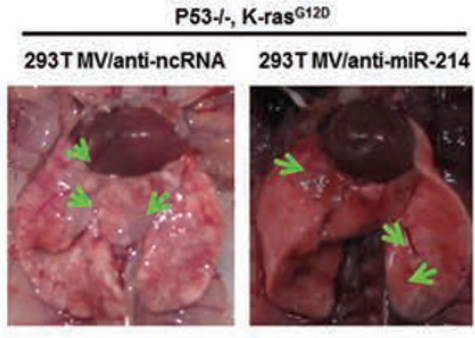

$\mathbf{F}$

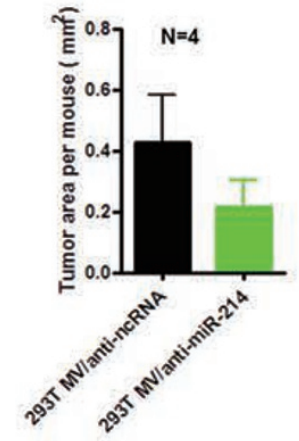

\section{G \\ Gate : CD4'Tcells}

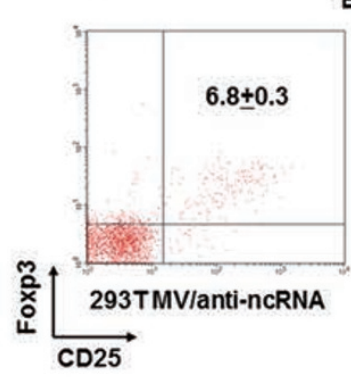
Blood

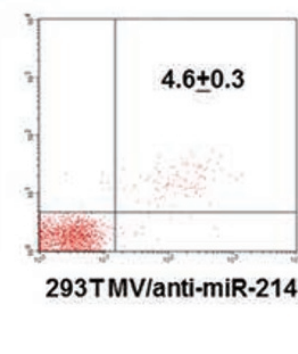

H

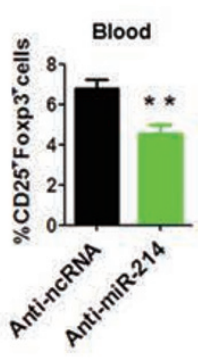

Gate: CD4+Tcells

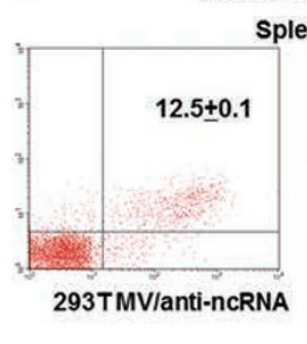

Spleen

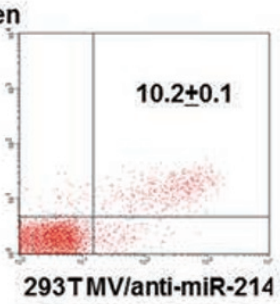

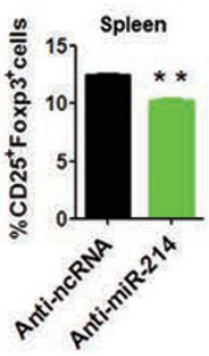

I

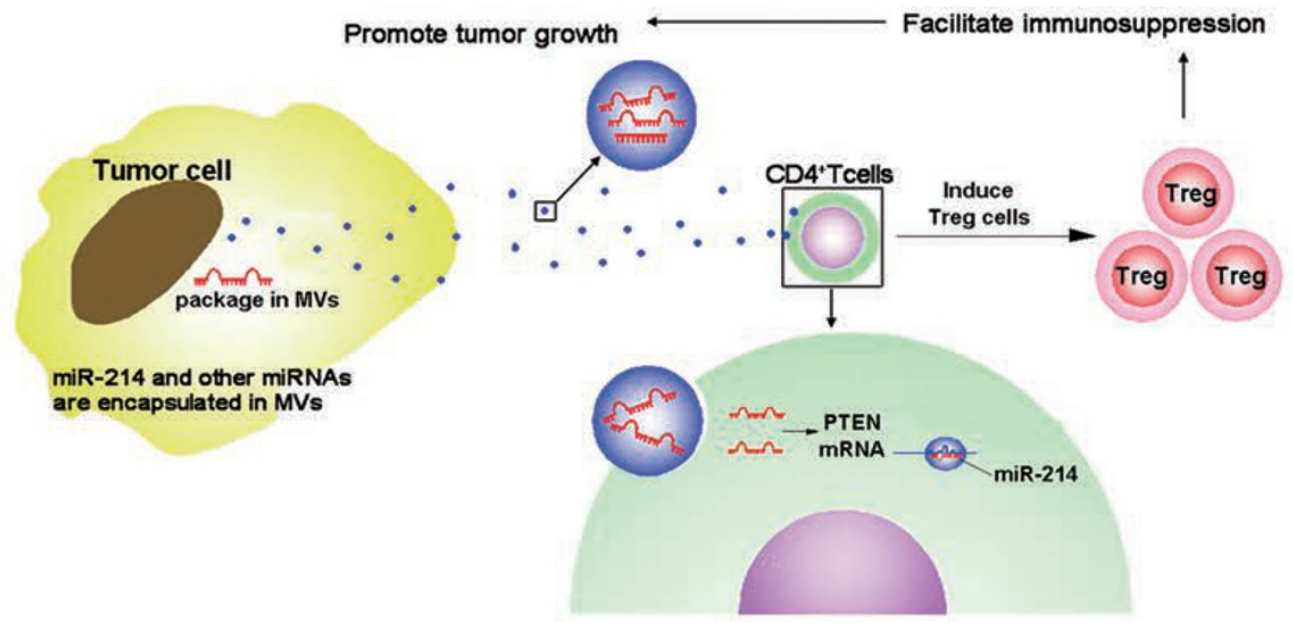


suppress tumor growth. We utilized 293T cells because they contain low levels of miR-214. We generated 293T MVs containing anti-miR-214 ASOs by transfecting 293 T cells with anti-miR-214 ASOs. Transfection of anti-miR-214 ASOs into the 293T cells did not substantially affect the protein, mRNA, or miRNA levels in the 293T MVs (Supplementary information, Figure S13A-S13C). The mice were implanted with S-180 cells and then treated with anti-miR-214 ASO-containing 293T MVs as depicted in Supplementary information, Figure S14A. As expected, treatment with the anti-miR-214 ASOs significantly decreased sarcoma-induced miR-214 levels in $\mathrm{CD}^{+} \mathrm{T}$ cells (Supplementary information, Figure S13D). Consequently, treatment with the anti-miR-214 ASOs successfully rescued the S-180 sarcoma-induced reduction of PTEN levels (Supplementary information, Figure S14B) and thus suppressed the expansion of $\mathrm{CD} 4^{+} \mathrm{CD} 25^{\text {high }} \mathrm{Foxp}^{+}$Tregs (Supplementary information, Figure S14C and S14D). Importantly, compared with the control mice treated with saline or 293T MVs containing a control oligonucleotide (anti-ncRNA), the mice treated with anti-miR-214 ASO-containing 293T MVs exhibited a significantly decreased growth rate and tumor size (Supplementary information, Figure S14E-S14G).

Next, we tested the effect of miR-214 in a de novo mouse model that spontaneously develops lung tumors [31-34]. This de novo lung cancer mouse model is sufficient to drive lung adenoma formation with the continuous activation of $K-$ ras $^{G 12 D}$ and loss of $p 53$ function in vivo by Adeno-Cre treatment. First, we measured the expression levels of miR-214 in $\mathrm{CD}^{+} \mathrm{T}$ cells and plasma from $p 53^{-/}, K$-ras ${ }^{G 12 D}$ mice. The results indicate that the miR-214 levels in the $\mathrm{CD}^{+} \mathrm{T}$ cells and plasma from the $p 53^{-/-}, K-\operatorname{ras}^{G 12 D}$ mice were significantly higher than those in wild-type mice (Figure 7A). We next used the $p 53^{1-}, K$ $\operatorname{ras}^{G 12 D}$ mouse model to test the effects of MV delivery of anti-miR-214 ASOs. Anti-miR-214 ASO treatment prevented weight loss in the $p 53^{-/-}, K$-ras ${ }^{G I 2 D}$ mice (Figure 7B). Compared with the $p 53^{-/-}, K-$ ras $^{G I 2 D}$ mice treated with 293T MVs containing anti-ncRNA, the $p 53^{-/-}, K-$ $\operatorname{ras}^{G 12 D}$ mice treated with the anti-miR-214 ASO-containing 293T MVs displayed decreased growth of spontaneous lung tumors (Figure 7C-7F). Anti-miR-214 ASOs also successfully suppressed the expansion of $\mathrm{CD} 4^{+} \mathrm{C}$ $\mathrm{D} 25^{\text {high }} \mathrm{Foxp} 3^{+}$Tregs in the blood and spleen of $p 53^{-/}, K$ $\operatorname{ras}^{G 12 D}$ mice (Figure $7 \mathrm{G}$ and $7 \mathrm{H}$ ). These results indicate that MV delivery of anti-miR-214 ASOs is an efficient method to abolish tumor-induced Treg expansion and inhibit the growth of tumors.

\section{Discussion}

Investigations of the biological functions of cell-secreted miRNAs are in their infancy. While secreted miRNAs in MVs have been shown to function as novel components of the intercellular communication system, the role of secreted miRNAs in tumor progression has only recently been investigated. In the present study, we report a new signaling pathway between tumor and immune cells. As a result of this type of intercellular communication, tumor cell-secreted miRNAs play a fundamental role in tumorigenesis by suppressing the immune response in host cells, which in turn accelerates tumor growth. Interestingly, some recent studies have shown that tumor-secreted miRNAs can participate in tumor spread or promote muscle loss during tumorigenesis [35, 36]. These studies, combined with us, reveal the importance of tumor-secreted miRNAs as a novel regulator in cancer progression.

A significant alteration of miRNA expression profiles is a major feature of tumorigenesis. As an oncogenic miRNA, miR-214 is upregulated in various types of

Figure 7 The inhibition of spontaneous lung tumor progression in $p 53^{-/}, K-$ ras $^{G 12 D}$ mice by $293 \mathrm{~T}$ MVs containing anti-miR-214 ASOs. (A) qRT-PCR analysis of the miR-214 levels in the CD4 ${ }^{+} \mathrm{T}$ cells and plasma of $p 53^{-/-}, K$-ras ${ }^{G 12 D}$ mice compared with wild-type mice. (B) The $p 53^{-/-}, K$-ras ${ }^{G 12 D}$ mice were treated with Adeno-Cre at week 8 . After 5 weeks of Adeno-Cre treatment, the mice were then treated with 293T MVs derived from 293T cells transfected with anti-ncRNA or anti-miR-214 ASOs (MV with $20 \mu \mathrm{g}$ of total protein in $100 \mu \mathrm{l}$ of PBS per mouse) once every 2 days for 2 weeks. The mice were then sacrificed and analyzed. A total of four mice were used in each group for the anti-ncRNA or anti-miR-214 treatment experiment. The body weights of the $p 53^{-/-}, K$-ras ${ }^{G 12 D}$ mice treated with anti-ncRNA or anti-miR-214 for 2 weeks were recorded. (C) Lung tumor formation in $p 53^{-/}, K_{-}$ras $^{G 12 D}$ mice treated with 293T MVs derived from 293T cells transfected with anti-ncRNA or anti-miR-214 for 2 weeks. (D) Pathological photos of the lung tumors from the $p 53^{-/-}, K-r a s^{G 12 D}$ mice that were treated with $293 T$ MVs derived from 293T cells transfected with anti-ncRNA or anti-miR-214 for 2 weeks. Scale bars: $500 \mu \mathrm{m}$ (top panels) and 100 $\mu \mathrm{m}$ (bottom panels). (E, F) The tumor number and area were evaluated for each mouse. (G, H) Flow cytometric analysis of the numbers of Tregs in the whole blood and spleen of $p 53^{-/-}, K-$ ras $^{G 12 D}$ mice treated with 293T MVs derived from $293 T$ cells transfected with anti-ncRNA or anti-miR-214 for 2 weeks. ${ }^{*} P<0.05$, ${ }^{* *} P<0.01$. (I) Working model for the role of tumor-secreted miR-214 in the conversion of $\mathrm{CD} 4^{+} \mathrm{T}$ cells into immune-suppressive Tregs and promotion of tumor immune escape. 
tumors [37, 38] and induces cell survival and cisplatin resistance in human cancers by targeting the $3^{\prime}$ UTR of PTEN, which leads to the activation of the Akt pathway. In the present study, we confirmed the elevated expression of miR-214 in different human cancer tissues (Figure 1A). Increased levels of plasma miR-214 were also detected in cancer patients (Figure 1B) and tumor-implanted mice (Figure $1 \mathrm{E}$ and $1 \mathrm{G}$ ), suggesting that circulating miR-214 may be secreted by tumor cells. Furthermore, we observed that the majority of the plasma miR-214 was stored in MVs (Figure $1 \mathrm{C}, 1 \mathrm{~F}$ and $1 \mathrm{H}$ ), by which miRNAs can be delivered into other cells and tissues. Because miR-214 is a major oncogenic miRNA and its levels are generally elevated in the plasma of various cancer patients, the signaling events induced by tumor-secreted miR-214 may serve as a common mechanism in various cancer cells to create a tumor-promoting microenvironment.

The following results suggest a direct delivery of tumor-secreted miR-214 into $\mathrm{CD} 4^{+} \mathrm{T}$ cells through an MV-mediated pathway. (a) Treatment with the LLC MVs increased the levels of miR-214 but not pre-miR-214 in the recipient $\mathrm{CD}^{+} \mathrm{T}$ cells (Figure 2 and Supplementary information, Figures S8 and S9). By contrast, treatment with MVs that contained deficient miR-214 did not upregulate miR-214 in $\mathrm{CD}^{+} \mathrm{T}$ cells (Supplementary information, Figure S7B). (b) The intravenous injection of fluorescently labeled tumor-derived MVs into mice resulted in the association of the fluorescent MVs with peripheral $\mathrm{CD}^{+} \mathrm{T}$ cells (Figure 5A). (c) Similarly, the administration of tumor MVs containing a mutant miR214 significantly increased the amount of mutant miR214 in the peripheral $\mathrm{CD}^{+} \mathrm{T}$ cells of mice (Figure 5B$5 \mathrm{E})$. Because most of the tumor cells expressed high levels of miR-214, the secretion of miR-214 by the tumor cells and the delivery of secreted miR-214 from the tumor cells to $\mathrm{CD}^{+} \mathrm{T}$ cells via the MVs may represent a common mechanism for cancers.

$\mathrm{CD} 4{ }^{+} \mathrm{CD} 25^{\text {high }} \mathrm{Foxp}^{+}$Tregs are a subset of $\mathrm{CD} 4^{+} \mathrm{T}$ cells that play an important role in maintaining self-tolerance and modulating immune responses in both normal and disease states $[3-5,39]$. Because PTEN is a direct target of miR-214 $[13,25]$ and the targeted depletion of PTEN can regulate peripheral homeostasis of $\mathrm{CD}^{+} \mathrm{C}$ $\mathrm{D} 25^{\text {high }} \mathrm{Foxp}^{+}$Tregs in vivo and their expansion ex vivo [28], tumor-secreted miR-214 may play a role in Treg expansion. In agreement with previous studies, our in vitro assay indicated that the expansion of Tregs could be induced by molecules that were present in the tumor-derived MVs, which likely included miR-214. Subsequently, we clearly demonstrated that the LLC MVs that contained high levels of miR-214 decreased the protein levels of PTEN in $\mathrm{CD}^{+} \mathrm{T}$ cells and increased the percentage of $\mathrm{CD}^{+} \mathrm{CD} 25^{\text {high }} \mathrm{Foxp}^{+}$Tregs in a dose-dependent manner (Figure 3A). The effects of the LLC MVs on the levels of PTEN and $\mathrm{CD} 4{ }^{+} \mathrm{CD} 25^{\text {high }} \mathrm{Foxp} 3^{+}$ Tregs were reversed by depleting miR-214 in the LLC MVs (Figure 3B and Supplementary information, Figure $\mathrm{S} 6 \mathrm{~B})$. These results further indicate that PTEN in $\mathrm{CD}^{+} \mathrm{T}$ cells was specifically targeted by the cancer cell-secreted miR-214. Our results indicate that secreted miR-214 targets PTEN and may serve as a critical "switch" molecule in Treg expansion, similar to previous reports that PTEN is a negative regulator of Treg expansion [28]. The activation of $\mathrm{CD} 44^{+} \mathrm{CD} 25^{\text {high }}$ Foxp $3^{+}$Tregs has a profound inhibitory effect on $\mathrm{T}$ cell-mediated immunity, particularly on $\mathrm{CD}^{+}$and $\mathrm{CD}^{+} \mathrm{T}$ cell function $[6,40,41]$. Several mechanisms, including the secretion of IL-10 and TGF- $\beta$ and/or direct cell-cell contact, have been proposed to explain the suppression of effector immunocytes by Tregs [5]. Because the treatment of $\mathrm{CD}^{+}{ }^{+} \mathrm{T}$ cells with the LLC MVs resulted in an increase in IL-10 but not IL-12 or TGF- $\beta$ (Figure 4A-4C), our results suggest the involvement of IL-10 in the suppression of the immune system by tumor-induced Tregs.

Tumor cells utilize two major mechanisms to evade the immune response: (a) modification of the tumor cells themselves to decrease their sensitivity to attacks by functional immune cells [1], and (b) direct modulation of the host immune cells to secrete cytokines such as TGF- $\beta$ and IL-10 [2]. The expansion of $\mathrm{CD} 4^{+} \mathrm{CD} 25^{\text {high }}$ Foxp $3^{+}$ Tregs is one of the major mechanisms used by cancer cells to suppress immune cell function and facilitate tumor immune evasion $[42,43]$. In tumor patients, levels of $\mathrm{CD}^{+} \mathrm{CD} 25^{\text {high }} \mathrm{Foxp}^{+}$Tregs are generally increased and associated with compromised immune responses [6]. Although multiple factors, such as IL-2 [10] and TGF- $\beta$ $[11,12]$, have been identified as being responsible for Treg expansion, the precise mechanisms that are responsible for the induction of tumor-associated Tregs remain poorly understood. Here, we present evidence suggesting that cancer cell-secreted miR-214 could expand the $\mathrm{CD} 4{ }^{+} \mathrm{CD} 25^{\text {high }}$ Foxp $3^{+}$Treg population by decreasing the levels of PTEN in $\mathrm{CD}^{+} \mathrm{T}$ cells, which may promote tumor growth (Figure 6 and Supplementary information, Figure S10). The secretion of miRNAs by cancer cells to target immune cells and alter the immune system represents a novel pathway for tumor immune evasion. On the other hand, it is also possible that tumor-secreted miR-214 enters into other cells (e.g., effector T cells, macrophages, NK cells, and tumor cells), in which miR214 may have different effect. Because peripheral T cells and tumor-secreted miR-214 are both in circulation, peripheral $\mathrm{T}$ cells may have more ample access to miR-214 
compared to other cells in different organs/tissues. By directly tracking exogenous miR-214 both in vitro and in vivo, our data clearly show that tumor cell-secreted miR214 can sufficiently enter into $\mathrm{CD}^{+} \mathrm{T}$ cells (Figure 5) and modulate PTEN expression and target cell function (Figures 3 and 6). Combining with our result that isolated $\mathrm{CD} 4^{+} \mathrm{T}$ cells can be directly converted into Tregs by miR-214-containing MVs (Figures 2 and 6), we conclude that downregulation of PTEN in $\mathrm{CD}^{+} \mathrm{T}$ cells and the expansion of Tregs are likely direct effects of miR-214 delivered by tumor MVs. Thus, tumor-secreted miR-214 inducing Tregs is one of major pathways to promote immune evasion and tumor growth.

Because Tregs are essential in tumorigenesis, the modulation of Tregs is an important area of research for the effective treatment of tumors. To evoke effective antitumor immunity, $\mathrm{CD} 44^{+} \mathrm{CD} 25^{\text {high }} \mathrm{Foxp} 3^{+}$Tregs have been depleted with anti-CD25 antibodies [44] or the recombinant IL-2 diphtheria toxin conjugate $\mathrm{DAB}_{389} \mathrm{IL}-2$ [45]. A recent study also employed the adenovirus-mediated intratumoral expression of immunostimulatory proteins in combination with systemic $\mathrm{CD} 4{ }^{+} \mathrm{CD} 25^{\text {high }} \mathrm{Foxp} 3^{+}$Treg inactivation to induce tumor-destructive immune responses in mouse models [46]. Although the results were promising, human Treg-based therapies have previously been difficult to implement in the clinic, and relatively few clinical trials have been initiated. Because our results suggest that the expansion of the $\mathrm{CD} 4^{+} \mathrm{CD} 25^{\text {high }} \mathrm{Foxp}^{+}$ Treg population by tumor-secreted miR-214 likely serves as a common mechanism for various cancer cells to create a tolerant immune environment, inhibiting the transport of tumor-secreted miR-214 to immune cells may be a novel strategy to reverse tumor-induced immune tolerance. By employing cell-derived MVs to deliver anti-miR-214 ASOs into peripheral $\mathrm{CD}^{+}{ }^{+} \mathrm{T}$ cells, we successfully reversed the downregulation of PTEN in CD4 $4^{+}$ $\mathrm{T}$ cells and blocked the expansion of the $\mathrm{CD} 4^{+} \mathrm{CD} 25^{\text {high- }}$ Foxp $3^{+}$Treg population (Figure 7 and Supplementary information, Figure S14). As expected, the MV-delivered anti-miR-214 ASOs effectively decreased the growth of the implanted and spontaneous tumors (Figure 7 and Supplementary information, Figure S14). In fact, MVs are natural nanocarriers derived from endogenous cells and would therefore be better tolerated by the immune system. Moreover, MVs protect small RNAs against RNase digestion and contain proteins that are required for small RNA function, such as Argonaute 2 (AGO2) [18, 47]. Thus, MVs have the intrinsic ability to traverse biological barriers and naturally transport functional small RNAs (including miRNA and siRNA) between cells. MV-mediated small RNA delivery may fill the void left by current delivery methods for systemic gene therapy.
In summary, our study provides the first evidence that tumor cells can actively modulate immune cell function through the secretion of MVs containing tumor-specific miR-214. As depicted in Figure 7I, tumor cells secrete miR-214 as well as other tumor-specific miRNAs through MVs that are then delivered into the peripheral $\mathrm{CD} 4^{+} \mathrm{T}$ cells. After the MVs enter the recipient $\mathrm{CD} 4^{+} \mathrm{T}$ cells, miR-214 decreases PTEN protein expression and facilitates Treg expansion, which, in turn, results in host immune suppression and tumor growth. Thus, tumor-secreted miRNA targeting of immune cells and the immune system represents an active pathway for tumor immune evasion. As an extension of this idea, we demonstrated that the inhibition of Treg-mediated immune suppression induced by tumor-secreted miR-214 via MV delivery of functional anti-miR-214 ASOs into $\mathrm{CD}^{+} \mathrm{T}$ cells represents a novel and effective therapeutic approach for cancer treatment.

\section{Materials and Methods}

\section{Cell culture}

LLC and 293T cells were purchased from the China Cell Culture Centre (Shanghai, China). The cells were cultured in high-glucose (4.5 g/L) DMEM (Gibco, Invitrogen, China) supplemented with $10 \%$ fetal bovine serum (FBS) (Gibco), penicillin, and streptomycin in a $5 \% \mathrm{CO}_{2}$ water-saturated atmosphere. The S-180 mouse sarcoma cell line was obtained from the China Cell Culture Centre, grown and maintained in RPMI-1640 medium (Gibco) supplemented with $10 \%$ FBS.

\section{Mice}

The 6-8-week-old male C57BL/6J mice were purchased from the Model Animal Research Centre of Nanjing University (Nanjing, China) and maintained under specific pathogen-free conditions at Nanjing University. The 7-week-old male nude mice were provided by the Experimental Animal Centre of Nanjing General Hospital (Nanjing, China). The Foxp $3^{\text {DTR }}$ mice (where DTR is diphtheria toxin receptor) were generously provided by Prof Alexander Rudensky (Memorial Sloan-Kettering Cancer Center, New York) and maintained under specific pathogen-free conditions at Nanjing University.

To generate the heterotypic tumor model, S-180 mouse sarcoma cells were subcutaneously injected into the left armpits of the animals. After the tumors were separated from the animals, the length, width, and height of the tumors was measured with digital calipers. The tumor weights were determined, and the ellipsoid volume was calculated using the following formula: Volume $=\pi / 6 \times$ (length) $\times($ width $) \times($ height $)$. All animal care and handling procedures were performed in accordance with the National Institutes of Health's Guide for the Care and Use of Laboratory Animals and were approved by the Institutional Review Board of Nanjing University.

The $L S L-K-r a S^{G I 2 D}$ and $p 53 L / L$ mice were originally generously provided by $\mathrm{T}$ Jacks (Massachusetts Institute of Technology) [31-34]. All mice were housed in a specific pathogen-free environ- 
ment at the Shanghai Institute of Biochemistry and Cell Biology and treated in strict accordance with protocols approved by the Institutional Animal Care and Use Committee of the Shanghai Institute of Biochemistry and Cell Biology, Chinese Academy of Sciences.

\section{Statistical analysis}

All of the western blot images and semi-quantitative qRT-PCR results are representative of at least three independent experiments. The real-time PCR and cell migration assays were performed in triplicate, and each experiment was repeated several times. The data are presented as the means \pm SEM of at least three independent experiments. The differences were considered statistically significant if $P$ was $<0.05$ by Student's $t$-test.

For all the other materials and methods, see Supplementary information, Data S1 for details.

\section{Acknowledgments}

We thank Prof Alexander Rudensky (Memorial Sloan-Kettering Cancer Center, New York) for diphtheria toxin-treated Foxp3 ${ }^{\text {DTR }}$ mice. We thank Drs Zheng-Gang Liu (Cancer Research Institute, $\mathrm{NIH}$ ) and Dan Wu (Yale University) for their comments on the manuscirpt. This work was supported by grants from the National Basic Research Program of China (973 Program; 2014CB542300), the National Natural Science Foundation of China (81101330, 31271378 and 81250044), the Natural Science Foundation of Jiangsu Province (BK2011013 and BK2012014) and the Research Special Fund for Public Welfare Industry of Health (201302018). This work was also supported by the program for New Century Excellent Talents in University from the Ministry of Education of China (NCET-12-0261).

\section{References}

1 Algarra I, Garcia-Lora A, Cabrera T, Ruiz-Cabello F, Garrido F. The selection of tumor variants with altered expression of classical and nonclassical MHC class I molecules: implications for tumor immune escape. Cancer Immunol Immunother 2004; 53:904-910.

2 Clark RA, Huang SJ, Murphy GF, et al. Human squamous cell carcinomas evade the immune response by down-regulation of vascular E-selectin and recruitment of regulatory $\mathrm{T}$ cells. J Exp Med 2008; 205:2221-2234.

3 Bach JF. Regulatory T cells under scrutiny. Nat Rev Immunol 2003; 3:189-198.

4 Sakaguchi S. Naturally arising $\mathrm{CD} 4^{+}$regulatory $\mathrm{t}$ cells for immunologic self-tolerance and negative control of immune responses. Annu Rev Immunol 2004; 22:531-562.

5 Sakaguchi S, Yamaguchi T, Nomura T, Ono M. Regulatory T cells and immune tolerance. Cell 2008; 133:775-787.

$6 \mathrm{Fu} \mathrm{J}, \mathrm{Xu} \mathrm{D}, \mathrm{Liu} \mathrm{Z}$, et al. Increased regulatory T cells correlate with CD8 T-cell impairment and poor survival in hepatocellular carcinoma patients. Gastroenterology 2007; 132:23282339.

7 Gallimore A, Godkin A. Regulatory T cells and tumour immunity - observations in mice and men. Immunology 2008; 123:157-163.

8 Quezada SA, Peggs KS, Simpson TR, Shen Y, Littman DR,
Allison JP. Limited tumor infiltration by activated T effector cells restricts the therapeutic activity of regulatory $\mathrm{T}$ cell depletion against established melanoma. J Exp Med 2008; 205:2125-2138.

9 Zhou Q, Bucher C, Munger ME, et al. Depletion of endogenous tumor-associated regulatory $\mathrm{T}$ cells improves the efficacy of adoptive cytotoxic T-cell immunotherapy in murine acute myeloid leukemia. Blood 2009; 114:3793-3802.

10 Malek TR, Yu A, Vincek V, Scibelli P, Kong L. CD4 regulatory $\mathrm{T}$ cells prevent lethal autoimmunity in IL-2Rbeta-deficient mice. Implications for the nonredundant function of IL-2. Immunity 2002; 17:167-178.

11 Andersson J, Tran DQ, Pesu M, et al. $\mathrm{CD}^{+} \mathrm{FoxP}^{+}$regulatory $\mathrm{T}$ cells confer infectious tolerance in a TGF-beta-dependent manner. J Exp Med 2008; 205:1975-1981.

12 Lohr J, Knoechel B, Abbas AK. Regulatory T cells in the periphery. Immunol Rev 2006; 212:149-162.

13 Chen CZ, Li L, Lodish HF, Bartel DP. MicroRNAs modulate hematopoietic lineage differentiation. Science 2004; 303:8386.

14 Lindsay MA. microRNAs and the immune response. Trends Immunol 2008; 29:343-351.

15 Rouas R, Fayyad-Kazan H, El Zein N, et al. Human natural Treg microRNA signature: role of microRNA-31 and microRNA-21 in FOXP3 expression. Eur J Immunol 2009; 39:16081618.

16 Divekar AA, Dubey S, Gangalum PR, Singh RR. Dicer insufficiency and microRNA-155 overexpression in lupus regulatory T cells: an apparent paradox in the setting of an inflammatory milieu. J Immunol 2011; 186:924-930.

17 Kohlhaas S, Garden OA, Scudamore C, Turner M, Okkenhaug $\mathrm{K}$, Vigorito E. Cutting edge: the Foxp3 target miR-155 contributes to the development of regulatory T cells. J Immunol 2009; 182:2578-2582.

18 Zhang Y, Liu D, Chen X, et al. Secreted monocytic miR-150 enhances targeted endothelial cell migration. Mol Cell 2010; 39:133-144.

19 Volinia S, Calin GA, Liu CG, et al. A microRNA expression signature of human solid tumors defines cancer gene targets. Proc Natl Acad Sci USA 2006; 103:2257-2261.

20 Al-Nedawi K, Meehan B, Rak J. Microvesicles: messengers and mediators of tumor progression. Cell Cycle 2009; 8:20142018.

21 Qin YJ, Buermans HPJ, van Kester MS, et al. Deep-sequencing analysis reveals that the miR-199a2/214 cluster within DNM3os represents the vast majority of aberrantly expressed microRNAs in Sezary syndrome. J Investig Dermatol 2012; 132:1520-1522.

22 Flynt AS, Li N, Thatcher EJ, Solnica-Krezel L, Patton JG. Zebrafish miR-214 modulates Hedgehog signaling to specify muscle cell fate. Nat Genet 2007; 39:259-263.

23 Narducci MG, Arcelli D, Picchio MC, et al. MicroRNA profiling reveals that miR-21, miR486 and miR-214 are upregulated and involved in cell survival in Sezary syndrome. Cell Death Dis; 2:e151.

24 Cobb BS, Hertweck A, Smith J, et al. A role for Dicer in immune regulation. $J$ Exp Med 2006; 203:2519-2527.

25 Jindra PT, Bagley J, Godwin JG, Iacomini J. Costimulation-dependent expression of microRNA-214 increases the 
ability of T cells to proliferate by targeting Pten. $J$ Immunol 2010; 185:990-997.

26 Ha TY. The role of microRNAs in regulatory T Cells and in the immune response. Immune Netw; 11:11-41.

27 Iborra M, Bernuzzi F, Invernizzi P, Danese S. MicroRNAs in autoimmunity and inflammatory bowel disease: crucial regulators in immune response. Autoimmun Rev 2012; 11:305-14

28 Walsh PT, Buckler JL, Zhang J, et al. PTEN inhibits IL-2 receptor-mediated expansion of $\mathrm{CD} 4{ }^{+} \mathrm{CD} 25^{+}$Tregs. J Clin Invest 2006; 116:2521-2531.

29 Kim JM, Rasmussen JP, Rudensky AY. Regulatory T cells prevent catastrophic autoimmunity throughout the lifespan of mice. Nat Immunol 2007; 8:191-197.

30 Lahl K, Loddenkemper C, Drouin C, et al. Selective depletion of Foxp3+ regulatory $\mathrm{T}$ cells induces a scurfy-like disease. $J$ Exp Med 2007; 204:57-63.

31 Tuveson DA, Shaw AT, Willis NA, et al. Endogenous oncogenic K-ras(G12D) stimulates proliferation and widespread neoplastic and developmental defects. Cancer Cell 2004; 5:375-387.

32 Wang Y, Zhang Z, Lubet RA, You M. A mouse model for tumor progression of lung cancer in ras and p53 transgenic mice. Oncogene 2006; 25:1277-1280.

33 Gao Y, Xiao Q, Ma H, et al. LKB1 inhibits lung cancer progression through lysyl oxidase and extracellular matrix remodeling. Proc Natl Acad Sci USA 2010; 107:18892-18897.

34 Wang Z, Feng Y, Bardeesy N, Wong KK, Liu XY, Ji H. Temporal dissection of $\mathrm{K}-\mathrm{ras}(\mathrm{G} 12 \mathrm{D})$ mutant in vitro and in vivo using a regulatable K-ras(G12D) mouse allele. PLoS One 2012; 7:e37308.

35 Zhou W, Fong MY, Min Y, et al. Cancer-secreted miR-105 destroys vascular endothelial barriers to promote metastasis. Cancer Cell 2014; 25:501-515.

36 He WA, Calore F, Londhe P, Canella A, Guttridge DC, Croce CM. Microvesicles containing miRNAs promote muscle cell death in cancer cachexia via TLR7. Proc Natl Acad Sci USA 2014; 111:4525-4529.

37 Bar-Eli M. Searching for the 'melano-miRs': miR-214 drives melanoma metastasis. EMBO J 2011; 30:1880-1881.

38 Chan E, Patel R, Nallur S, et al. MicroRNA signatures differentiate melanoma subtypes. Cell Cycle 2011; 10:1845-1852.

39 Miyara M, Sakaguchi S. Natural regulatory T cells: mecha- nisms of suppression. Trends Mol Med 2007; 13:108-116.

40 Joffre O, Gorsse N, Romagnoli P, Hudrisier D, van Meerwijk JP. Induction of antigen-specific tolerance to bone marrow allografts with $\mathrm{CD} 4{ }^{+} \mathrm{CD} 25^{+} \mathrm{T}$ lymphocytes. Blood 2004; 103:4216-4221.

41 von Boehmer H. Mechanisms of suppression by suppressor T cells. Nat Immunol 2005; 6:338-344.

42 Huang B, Pan PY, Li Q, et al. Gr- $1^{+} \mathrm{CD} 115^{+}$immature myeloid suppressor cells mediate the development of tumor-induced $\mathrm{T}$ regulatory cells and T-cell anergy in tumor-bearing host. Cancer Res 2006; 66:1123-1131.

43 Valzasina B, Piconese S, Guiducci C, Colombo MP. Tumor-induced expansion of regulatory $\mathrm{T}$ cells by conversion of $\mathrm{CD} 4{ }^{+} \mathrm{CD} 25^{-}$lymphocytes is thymus and proliferation independent. Cancer Res 2006; 66:4488-4495.

44 Onizuka S, Tawara I, Shimizu J, Sakaguchi S, Fujita T, Nakayama E. Tumor rejection by in vivo administration of anti-CD25 (interleukin-2 receptor alpha) monoclonal antibody. Cancer Res 1999; 59:3128-3133.

45 Dannull J, Su Z, Rizzieri D, et al. Enhancement of vaccine-mediated antitumor immunity in cancer patients after depletion of regulatory T cells. J Clin Invest 2005; 115:36233633.

46 Liu Y, Tuve S, Persson J, et al. Adenovirus-mediated intratumoral expression of immunostimulatory proteins in combination with systemic Treg inactivation induces tumor-destructive immune responses in mouse models. Cancer Gene Ther 2011; 18:407-418.

47 Gibbings DJ, Ciaudo C, Erhardt M, Voinnet O. Multivesicular bodies associate with components of miRNA effector complexes and modulate miRNA activity. Nat Cell Biol 2009; 11:1143-1149.

(Supplementary information is linked to the online version of the paper on the Cell Research website.)

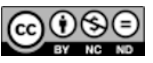
This work is licensed under the Creative Commons Attribution-NonCommercial-No Derivative Works 3.0 Unported License. To view a copy of this license, visit http:// creativecommons.org/licenses/by-nc-nd/3.0 